\title{
Preventing Societal Health Risks Emerging in the Development Of Nanomedicine - What Should Prevail?
}

\author{
Roberte Manigat ${ }^{1}$, Florent Allix², \\ Céline Frochot ${ }^{2}$ and Jean Claude André2,3 \\ ${ }^{1}$ Ministère du Travail, de l'Emploi et de la Santé, Paris, \\ ${ }^{2}$ Centre National de Recherche Scientifique LRGP-UPR 3349, Nancy, \\ ${ }^{3}$ Centre National de Recherche Scientifique INSIS, Paris,
}

France

\section{Introduction}

The traditional distinction between preventive and curative medicine has probably served, among others, programmatic and educational purposes, but does not look so robust (and valid) when used to back-up choices for innovative technologies or justify managerial economic options. Obviously, the line between both some secondary or tertiary preventive actions and many curative ones is often void, and above all a simple question of optical perspective.

Indeed, in our opinion, prevention and precaution are the underlying humanistic driving forces that have, or should have, always presided to the management of health risks. And this should remain untouched. Is this merely an ideological choice? In any case, the implementation of these concepts is also definitely not detrimental to long term economical considerations, another real asset, nor a limiting factor to progress and innovation.

Nanotechnology refers to the design, characterization, production and application of structures, devices and systems that have novel physical, chemical and biological properties, by controlling shape and size at the nanometer scale ${ }^{1}$ (Ebbesen and Jensen, 2006). While this multidisciplinary scientific field is undergoing explosive development, it is also subject to many controversial debates among scientists, but not only2. The design

\footnotetext{
${ }^{1}$ A nanometer $(\mathrm{nm})$ is equal to one billionth of a meter $\left(10^{-9}\right.$ meter $)$; formerly called millimicron $(1 / 1000$ of a micron), the nano scale was denoted by the symbol $\mathrm{m} \mu$. As an illustration, the diameter of a red blood cell is roughly 1000 nanometers (10-6 meter).

${ }^{2} \mathrm{~A} 3$ days Conference on Risks associated with nanoparticles and nanomaterials was organised by the French National Institute on Research and Security (INRS) in April 2011, to discuss occupational health research issues. A public debate on Nanotechnologies was held in France from October $15^{\text {th }} 2009$ to February 24th 2010, organized by the National Commission on Public Debate (CNDP) the National official and independent body (full details are available from:

http://www.debatpublicnano.org/index.html).
} 
and assembly of sub microscopic devices called nanoparticles, which are 1 to 100 nanometer in diameter (Kateb et al., 2011), are also the object of concern as to the safety of their use, and not only in the general public (Poland et al., 2008; Takagi et al., 2008; Genaidy et al., 2009; Murphy et al., 2011). Potential toxic effects of certain nanoproducts have legitimately conducted either the decision makers or the civil society to mobilise high level expert's investigation not only in France (AFSSET, 2006, 2008; HCSP, 2009) but in most of the OECD member countries (Kaluza et al., 2008; DHHS-CDC-NIOSH, 2009; Ostiguy et al., 2010). In either case, among the multiple fields of application of nanotechnology, we believe that the development of nanomedicine, the application of nanotechnology for the diagnosis and treatment of human disease, should be oriented through the lenses of the above mentioned driving forces, and subsequently handled with special care. If any, this field of research, whether fundamental or applied, calls for the implementation of principles qualified as socially responsible (André, 2008). Charters, codes of conduct, guidelines and other such documents, are slowly adopted by institutions $^{3}$ that promote Socially Responsible Research, introduced with various status (contractual or not) in their rules and procedures.

Today, not a single country is exempt from the consequences of the early $21^{\text {st }}$ century financial, economic and social crises which impact the capacities to pursue and meet the goals and objectives set globally, regionally or nationally for the health sector, both in terms of access to the health care system and improvement of the well being of the world population ${ }^{4}$. Funding issues, not only due to a trend towards aging of the world population, are among the challenges faced and choices have to be made among a variety of options. In our opinion, concentrating on the problems for which a sound alternative does not exist while privileging the most effective, efficient and sustainable measures probably represent the best strategic option. Decision makers, industrials, research institutions, non governmental organizations, many stakeholders claim that nanomedicine offers an excellent, innovative, and almost ideal solution to handle a lot of the medical problems faced by the world population, and at costs that can be contained (ETPN, 2006). Thus research in this discipline is evolving at a high speed.

Given our diverse respective skills and competencies, we chose to develop a case study on this specific field of application of nanotechnology, with special integrated inputs from each individual of the multidisciplinary team (photo chemist conducting research in basic sciences, risk management specialist, public health medical specialist), in order to develop an interdisciplinary expertise open to large societal needs.

\footnotetext{
${ }^{3}$ The European Charter for Researchers, edited in 2005 by the European Commission, has been adopted by many French research institutions, the National Centre for Scientific Research (CNRS) and the National Institute for Research in Agronomy (INRA) among others. Many other countries have also elaborated such document, Australia (Australian Code for Responsible Conduct of Research) and the USA (NIH Policy on instruction in the responsible conduct of research), among others.

${ }^{4}$ The 8 Millennium Development Goals (MDG), along with their quantified targets to be reached by 2015 for the vast majority, were adopted at the United Nations Millennium Summit in September 2000. Three of them, MDG 4 (Reduce child mortality), MDG 5 (Improve mental health), and MDG 6 (Combat HIV/ AIDS, malaria and other major diseases) address specifically health issues. According to the last report, released in July 2011, they are unlikely to be met, particularly in the most vulnerable populations.
} 
We will first give an overview of nanomedicine in order to better situate research on photodynamic therapy among the various objects covered by this field of application of nanotechnology. This whole descriptive phase is done in the second section. After introducing the nanomedicine taxonomy, we will present the principal historical and technical elements, starting from the broad perspective of drug delivery systems and/or materials, in the subsection on biopharmaceutical, and then moving to a more detailed one, in the sub-section on photodynamic therapy. We will present photodynamic therapy more extensively, since the development of nanoparticles for use in this cancer treatment modality, the object of the research conducted by some of the authors ${ }^{5}$, is at the foundation of our case study.

In the third section, centred on our case study, the design will be presented. The method and literature review will be introduced first. Then, in addition to a detailed presentation of the general framework, the research conducted by some of the authors, the content and implementation of a pilot survey that we conducted in June/July 2011 will be described. Our principal aim in doing that pilot survey was to dispose of first hand and shared information regarding the state of knowledge of our study object in the general educated public.

The results of our pilot survey will be analyzed in section four.

In the discussion, the following section, based on our professional experiences and using the main findings extracted from our pilot survey as illustrative arguments, we will highlight three management organizational modalities, the precautionary principle, knowledge management, and translational research, that we believe useful to implement in order to improve the risk management process in general, and the quality of our work, in particular.

We will close with some lessons learned from these management modalities, a few broad recommendations, and an opening on ethical and regulatory issues.

\section{An overview of nanomedicine}

The concept of using nanotechnology in medical research and clinical practice holds great values and opens real perspectives for effective innovations in medical sciences (Sandhiya et al., 2009). Considering the broad spectrum of the series of technologies that can be used individually or in combination to make products and applications and to better understand science, efforts in classification have been initiated (Table 1). One way of characterizing nanotechnology is by utilizing the following four segments: tools, materials, devices \& intelligent materials and machines. Those segments support the nanomedicine taxonomy developed by the Canadian Institutes of Health Research and the Canadian NanoBusiness Alliance (Gordon and Sagman, 2003). In a partial nanomedicine technologies taxonomy proposed in the beginning of this century, some of the most interesting and diverse current research projects within several of the 96 existing sub-categories were described (Freitas, 2005). The applications, which pertain to both medical and surgical diagnosis and therapeutic techniques, are as diverse as the development of nanoparticles for diagnostic and screening purposes, artificial receptors, DNA sequencing using nanopores, manufacture of unique drug

\footnotetext{
5 This refers to those of us from the Reactions and Chemical Engineering Laboratory of the National Center for Scientific Research.
} 
delivery systems, gene therapy, enablement of tissue engineering, and, single-virus detection (Emerich, 2005). Indeed, nanostructures, whether still under development or already in use, have the potential to play a critical role in the future of medicine, as they can be carriers for drugs, genes, and imaging agents as well as targeting units (Kateb et al., 2011).

The need for the development of a new framework, including regulations, procedures and mechanisms, adapted specifically to govern research in nanotechnology, thus nanomedicine, is as salient in Europe as in the United States. Heightened uncertainty regarding risks, fast-evolving science yielding complex and increasingly active materials, likelihood of research on vulnerable participants including cancer patients, and potential risks to others beyond the research participant are identified as relevant confluent factors in support of the need for an exceptional oversight beyond the existing Common Rules 6 supervised by either local or federal institutions such as the US Department of Health and Human Services, the Federal Drug Administration (FDA), notably its Centres in charge of overseeing drug, biologics, and device approval, the National Institutes of Health or the National Cancer Institute (Wolf and Jones, 2011). Concern regarding potential risks does not involve only the volunteers and candidates recruited to participate to clinical trials, but also workers employed in the manufacturing industries, as well as, during the fundamental research stage, scientists conducting experiments in public or private laboratories.

At the European level also, the existing corpus of regulations needs to be progressively adapted to risk management specifically applicable to research in nanomedicine, even if enforcement will not necessarily be mandatory in each individual Member State. In France, Committees for the Protection of Citizen7, structures similar to those existing in the US, are in place and the supporting laws under review.

Among the leading areas of research in nanomedicine summarized in the taxonomy (Table 1), biopharmaceutics offers an array of applications, with numerous drugs either already commercialised or still subject to ongoing research programmes, whether in the public or private sectors. Within this research area, the development of new materials or systems to optimize the deliver of the therapeutic agents is a steady option. The development of nanoparticles for photodynamic therapy falls under this category. Thus, in the following two sub-sections, we will highlight historical and technical elements, first on biopharmaceutical, then on photodynamic therapy.

\subsection{Biopharmaceutics}

Liposomes, spherical vesicles that can be produced from natural nontoxic phospholipids and cholesterol, are made of a lipid bilayer surrounding a water core hosting the drug. The first studies to report the efficiency of liposomes as nanoparticles focused on the improvement of pharmacokinetics and bio-distribution of doxorubicin. Approved by the FDA on November 17th 1995, Doxorubicin HCI Liposome injection, an anti-neoplastic drug administrable intravenously, is probably the first nanoscale drug delivery materials that

\footnotetext{
${ }^{6}$ Are identified as such the basic procedures existing since 1981 that rely mainly on Institutional Review Boards (IRB) and Data Safety Monitoring Boards or Committees.

${ }^{7}$ Comités de Protection des Personnes (CPP).
} 


\begin{tabular}{cccccc}
\hline \multicolumn{9}{c}{$\begin{array}{c}\text { Nanotechnology segments \& Nanomedicine Taxonomy } \\
\text { (Source: Gordon and Sagman, 2003) }\end{array}$} & \\
\hline Tools & Materials & Devices & $\begin{array}{c}\text { Intelligent } \\
\text { Materials \& } \\
\text { Machines }\end{array}$ \\
\hline $\begin{array}{c}\text { Microscopy } \\
\text { Techniques \& } \\
\text { Instruments }\end{array}$ & Raw & Nanostructured & Nanotubes \\
Naterials & Materials & $\begin{array}{c}\text { Nano \& Micro } \\
\text { devices }\end{array}$ & $\begin{array}{c}\text { (no application } \\
\text { expected soon) }\end{array}$
\end{tabular}

Fullerenes

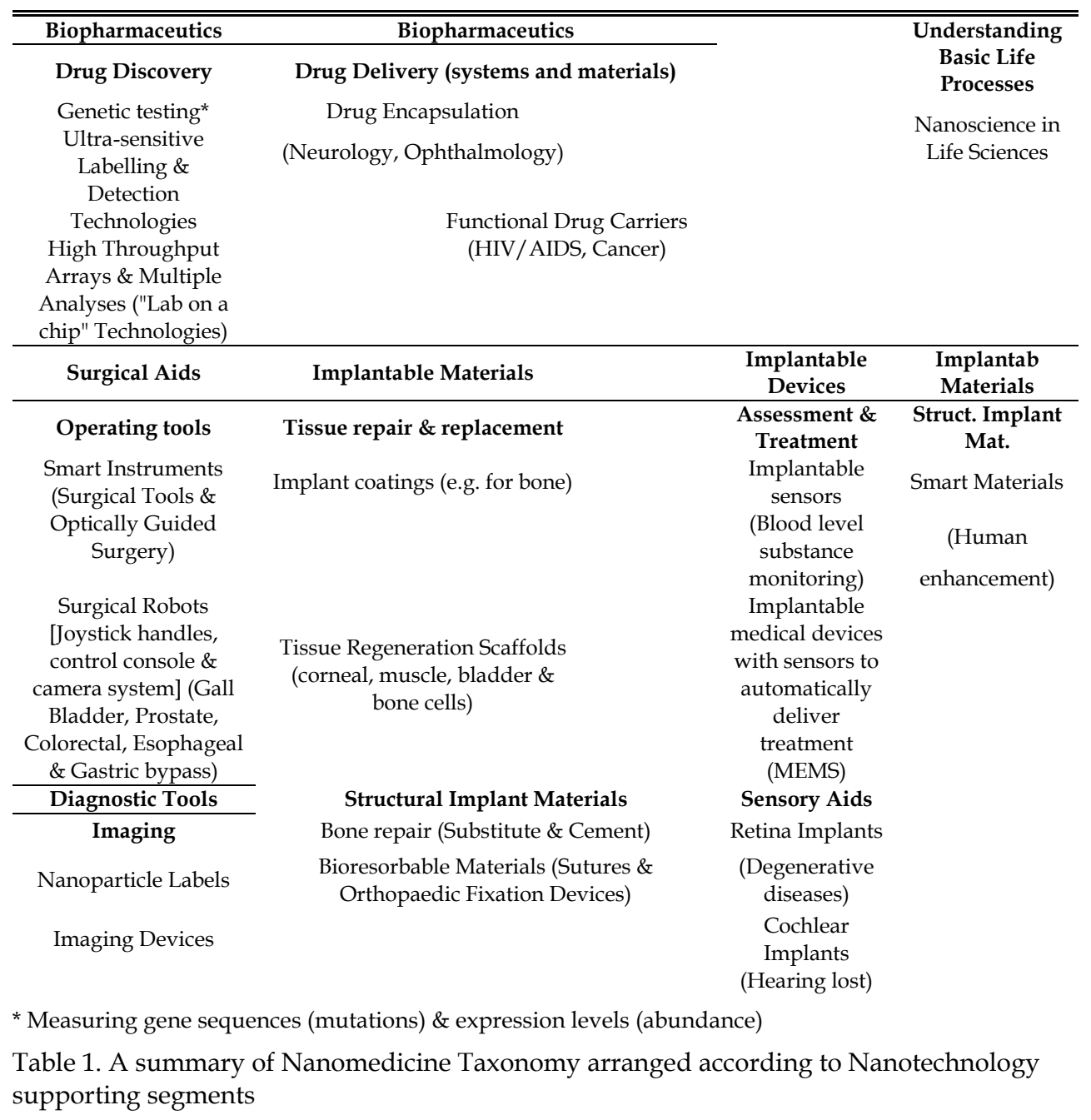

8 Original table adapted from the Nanomedicine Taxonomy. Potential inaccuracy may have occurred in the proposed synthesis, and some items of the Nanomedicine Taxonomy may belong to more than the segments under which they appear. 
reached the market (Table 2). Soon after during the same year, an antifungal, Amphotericin B Lipid Complex Injection, was approved. A significant number of drug products have been commercialized since then, including on platforms other than liposomal such as nanocrystal platforms, for various ill states (hypercholesterolemia, hypertriglyceridemia, anorexia etc.), and, in 2005, indicated in metastatic breast cancer, the first albumin nanoparticle was approved for human use (Wang and Thanou, 2010; Kateb et al., 2011).

\begin{tabular}{|c|c|c|c|c|}
\hline Platform & Generic name & Indication & $\begin{array}{c}\text { Route of } \\
\text { Administration }\end{array}$ & Approval date \\
\hline \multirow[t]{5}{*}{$\begin{array}{l}\text { Liposomal } \\
\text { platforms }\end{array}$} & Liposomal doxorubicin & $\begin{array}{l}\text { Ovarian and breast } \\
\text { cancer }\end{array}$ & $\begin{array}{c}\text { intra venous } \\
\text { (i.v.) }\end{array}$ & 17 November 95 \\
\hline & $\begin{array}{c}\text { Daunorubicin citrate liposome } \\
\text { injection }\end{array}$ & Anti neoplastic & i.v. & 8 April 96 \\
\hline & $\begin{array}{l}\text { Pegylated liposomal doxorubicin } \\
\text { hydrochloride }\end{array}$ & $\begin{array}{l}\text { Ovarian and breast } \\
\text { neoplasms } \\
\text { Kaposi's Sarcoma } \\
\text { Multiple myeloma }\end{array}$ & i.v. & 21 June $96^{*}$ \\
\hline & Verteporfin for injection & $\begin{array}{l}\text { PDT for age-related } \\
\text { macular } \\
\text { degeneration }\end{array}$ & & 12 April 00 \\
\hline & $\begin{array}{l}\text { Non-pegylated liposomal } \\
\text { doxorubicin formulation }\end{array}$ & Breast neoplasms & i.v. & 13 July $00^{*}$ \\
\hline \multicolumn{5}{|l|}{$\begin{array}{l}\text { Other } \\
\text { Platforms }\end{array}$} \\
\hline & Albumine taxol conjugate & $\begin{array}{c}\text { Metastatic breast } \\
\text { cancer }\end{array}$ & i.v. & 7 January 05 \\
\hline & $\begin{array}{c}\text { Dextran Ferumoxide injectable } \\
\text { solution Superparamagnetic Iron } \\
\text { Oxides Particles (SPIO) }\end{array}$ & $\begin{array}{c}\text { Magnetic } \\
\text { Resonance Imaging } \\
\text { (MRI) contrast } \\
\text { agent for the liver }\end{array}$ & i.v. & 1 February 96 \\
\hline & $\begin{array}{l}\text { Dextran coated iron oxide } \\
\text { Ultra small Superparamagnetic } \\
\text { Iron Oxides Particles (USPIO) }\end{array}$ & MRI contrast agent & i.v. & 3 March 05 \\
\hline
\end{tabular}

Table 2. Some of the main nanoscale drug product approved for cancer treatment and diagnosis by the Federal Drug Administration in the USA (Zolnik and Sadrieh, 2009 as cited in Kateb et al., 2011) and by the European Medicines Agency* for use in the European Union

Some key properties that make nanoscale liposome an excellent device for targeted drug delivery have been highlighted recently: they are biocompatible, biodegradable, not immunogenic, familiar to and mastered by the scientific community, have known pharmacokinetics, bio-distribution and metabolism. Therefore, from a toxicological stand point, they have advantages over other nanoproducts for medical pharmaceutical applications as well as consumer products in cosmetics and clean technology. Additionally, if introduced in excess, the liposomes may be destroyed by the macrophages, as seen in the natural course of their life cycle (Barenholz, 2010). Convincing, and that may also address the question of eliminating the product, if need be, to deal with an irreversible risk later identified. Thus, the research can be pursued until challenged by new discoveries. 
This leads us to introduce reversibility, another important factor that we consider worth exploring, besides the concerns that we previously mentioned as leading our interdisciplinary expertise: prevention and precaution as the underlying humanistic driving forces presiding to the management of health risks at short, medium and long terms, and, strategic research development options which promote the most equitable, effective, efficient and sustainable fields. These factors will be touched upon throughout the following sections, and in particular in the discussion, with extensive developments on three complementary approaches to consider in risk management applied to our case study: the precautionary principle, knowledge translation and translational research.

\subsection{Photodynamic therapy}

Photodynamic therapy (PDT) is another important emerging research field for the development of nanoscale therapeutics (Bechet et al., 2008; Couleaud et al., 2010b; Vanderesse et al., 2011) that can optimize drug delivery of materials or systems. Photodynamic therapy involves the use of light, photosensitizers and oxygen. The photosensitizers, after excitation with light of an appropriate wavelength, can transfer their energy from their triplet excited state to neighboring oxygen molecules (Ortel et al., 2009). Reactive Oxygen Species (ROS) and singlet oxygen $\left({ }^{1} \mathrm{O}_{2}\right)$, which is commonly accepted to be the main cytotoxic species, are formed and lead to the destruction of cancer cells by both apoptosis and necrosis. PDT efficiency depends on the photosensitizer's ability to produce ROS and ${ }^{1} \mathrm{O}_{2}$, availability (Verhille et al., 2010), light dose and photosensitizer concentration in the treated area.

Used in dermatology to treat basal cell carcinomas as early as the beginning of last century, the application of this treatment modality stayed somehow confidential for quite a while, but PDT is now established as a clinical treatment modality for various diseases including cancer (Dougherty et al., 1998; Triesscheijn et al., 2006). PDT is currently being developed as a treatment for cancer of the esophagus, bronchi, and bladder, as well as for other non oncological applications, such as age-related macular degeneration (Agostinis et al., 2011), and is also used as a successful non-invasive therapeutic modality for treating cutaneous neoplasm. In France, research on PDT is developed within different laboratories from the National Centre for Scientific Research, with four main hubs located respectively in the Parisian Region (Evry, Orsay), Lille, Nancy and Toulouse. A partnership has been officialised for 4 years in 2007, with the establishment of a research network within the National Centre for Scientific Research's Institute of Chemistry. Recognized by the acronym GDR ${ }^{9}$, the objective of the research network is to develop medicines that can be activated by light along with their therapeutic applications.

The first photosensitizer to have received approval for use in PDT was porfimer sodium, authorized for the treatment of superficial bladder cancer in Canada in 1993, and later for early lung and advanced esophageal cancers in Netherlands and Japan (Triesscheijn et al., 2006). Over the past decade, various types of photosensitizers have been developed in order to improve their properties (light absorption and diseased tissues selectivity) compared to the original first-generation ones (Table 3).

${ }_{9}^{9}$ Groupement de Recherche (GDR) 3049 PHOTOMED Médicaments Photoactivables -

Photochimiothérapies. More information available from the web site at:

http://www.gdr-photomed.cict.fr/spip.php?rubrique1. 


\begin{tabular}{|c|c|c|c|c|}
\hline Photosensitizer* & Cancer types & Chemical structure & $\begin{array}{c}\text { Excitation } \\
\text { wavelength } \\
(\mathrm{nm})\end{array}$ & Approved \\
\hline \multicolumn{5}{|c|}{ First generation } \\
\hline $\begin{array}{l}\text { Porfimer sodium } \\
\text { (Photofrin)(HPD) }\end{array}$ & $\begin{array}{c}\text { Bile duct, Bladder, } \\
\text { Brain, Lung, } \\
\text { Oesophagus, Ovaries }\end{array}$ & Porphyrin & 630 & Yes \\
\hline \multicolumn{5}{|c|}{ Second generation } \\
\hline ALA & $\begin{array}{l}\text { Bladder, Brain, } \\
\text { Oesophagus, Skin }\end{array}$ & $\begin{array}{l}\text { Porphyrin precursor } \\
\text { (protoporphyrin IX) }\end{array}$ & 635 & Yes \\
\hline ALA esters & Bladder, Skin & $\begin{array}{l}\text { Porphyrin precursor } \\
\text { (protoporphyrin IX) }\end{array}$ & 635 & Yes \\
\hline $\begin{array}{c}\text { Temoporfin } \\
(\text { Foscan })(m \mathrm{THPC})\end{array}$ & $\begin{array}{l}\text { Bile duct, Brain, Head } \\
\text { and Neck, Lung, Skin }\end{array}$ & Chlorin & 652 & Yes \\
\hline $\mathrm{HPPH}$ & $\begin{array}{c}\text { Head and neck, Lung, } \\
\text { Oesophagus }\end{array}$ & Chlorin & 669 & \\
\hline SnEt2 (Purlytin) & Breast, Skin & Chlorin & 660 & \\
\hline $\begin{array}{c}\text { Mono-(L)- } \\
\text { aspartylchlorin-e6 } \\
\text { Talaporfin (LS11, } \\
\text { MACE, NPe6) }\end{array}$ & Brain, Colon, Liver & Chlorin & 660 & \\
\hline $\begin{array}{l}\text { Ce6-PVP (Fotolon), } \\
\text { Ce6 derivatives } \\
\text { (radachlorin, } \\
\text { photodithazine) } \\
\end{array}$ & $\begin{array}{l}\text { Brain, } \\
\text { Nasopharyngeal, } \\
\text { Sarcoma }\end{array}$ & Chlorin & 660 & \\
\hline $\begin{array}{c}\text { Silicon } \\
\text { phtalocyanine }\end{array}$ & $\begin{array}{c}\text { Cutaneous T-cell } \\
\text { lymphoma }\end{array}$ & Phtalocyanine & 675 & \\
\hline $\begin{array}{l}\text { Padoporfin } \\
\text { (Tookad) }\end{array}$ & Prostate & Bacteriochlorin & 762 & \\
\hline $\begin{array}{l}\text { Motexafin lutétium } \\
\text { (Lutex) }\end{array}$ & Breast & Texaphyrin & 732 & \\
\hline \multicolumn{5}{|c|}{ Third generation } \\
\hline $\begin{array}{l}\text { Verteporfin } \\
\text { (liposomal } \\
\text { formulation) }\end{array}$ & $\begin{array}{l}\text { Ophtalmic, Pancreas, } \\
\text { Skin }\end{array}$ & Chlorin & 690 & Yes \\
\hline \multicolumn{5}{|c|}{ Fourth generation (theranostic) } \\
\hline & & $\begin{array}{c}\text { Multifunctional } \\
\text { nanoparticle }\end{array}$ & & \\
\hline
\end{tabular}

*Abbreviations: HPD [Hematoporphyrin Derivative]; ALA [5-Aminolaevulinic Acid]; $m$ THPC [metatetra (hydroxyphenyl)chlorin]; HPPH [2-(1-hexyloxyethyl)-2-devinyl-pyropheophorbide]; SnEt2 [tin ethyl etiopurpurin]; Ce6 [chlorin e6]; PVP [ polyvinylpyrrolidone]

Table 3. Successive Generations of Photosensitizers used for the diagnostic or treatment of cancer with their main characteristics (Plaetzer et al., 2009; Agostinis et al., 2011)

A second-generation of photosensitizers, such as chlorins and phthalocyanines, present better light absorption in the red part of the visible light spectrum, which commonly represent the therapeutic window because of the slightest absorption of endogenous tissues compounds in this area (mainly hemoglobin and water). Thousands of patients have already been treated with PDT using the first and second generation of photosensitizers for a variety of advanced neoplasms, and the treatment induced a great improvement in their quality of 
life and lengthened their survival. Despite photophysical enhancements, the ability of these photosensitizers to discriminate between healthy cells and tumors remains low, leading to side effects such as photosensitivity in the presence of sunlight due to skin accumulation.

A third generation of photosensitizers has been developed, based on a strategy of selective delivery of the drug into diseased tissues. They consist of second-generation photosensitizers combined with targeting units such as oligo-nucleotides, peptides or monoclonal antibodies (Chen et al., 2006), or photosensitizers encapsulated into nanoplatforms. Nanoparticles represent emerging photosensitizer carriers really promising for use in PDT. In bionanotechnology, their development can overcome most of the shortcomings of classic photosensitizers. Potential advantages of nanoparticles are that a high "payload" can be delivered: they can transport hydrophobic drug in blood, their surface can be modified with functional group, they have a large volume of distribution and are generally taken up efficiently by cells, and, controlled release of drug is possible. It is commonly accepted that strategies used to deliver the photosensitizer specifically to diseased tissues using the target tissue receptors or antigens are termed "active", whereas other formulations that enable parenteral administration and passive targeting are termed "passive".

Many nanoplatforms are being studied in the field of PDT (Figure 1), some of which are biodegradable (Figure 1a-e) and others not (Figure $1 \mathrm{f}-\mathrm{l}$ ). The first nanodrug that reached the marked for use in PDT, approved in the USA by the FDA in April 2000, was a liposomal formulation, Verteporfin for injection, indicated for the treatment of predominantly classic subfoveal choroidal neovascularisation due to age-related macular degeneration, pathologic myopia or presumed ocular histoplasmosis (Table 2 and Figure 1e).
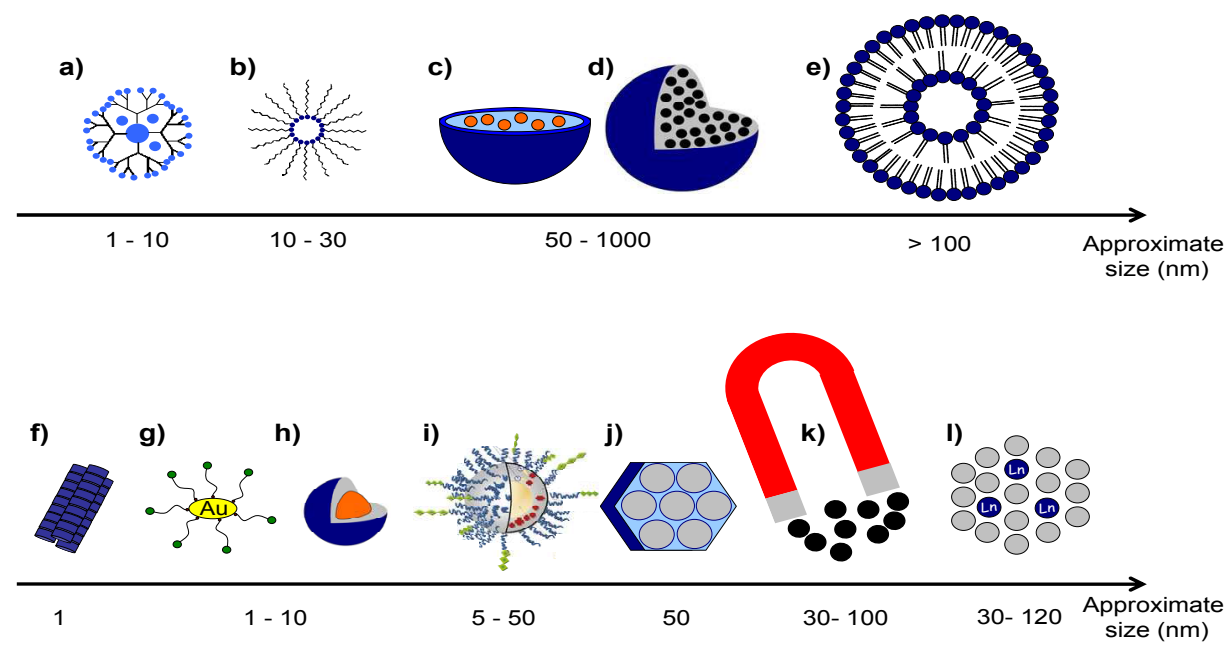

Biodegradable: a) dendrimers, b) polymeric micelles, c) polymeric capsules, d) polymeric nanospheres, e) liposomes,

Non biodegradable: f) carbon nanotubes, g) gold nanoparticles, h) quantum dots, i) silica nanoparticles, j) zeolite, k) magnetic nanoparticles, l) up-converting nanoparticles

Fig. 1. Main nanoplatforms used for cancer diagnosis and treatment in the field of PDT 
Among the many photosensitizing agents that are being elaborated, very few have made it to robust clinical trials. Although third generation photosensitizers have been widely described for selective targeting, very few have been evaluated for clinical applications as their in vivo selectivity was not high enough compared to the one demonstrated in vitro.

However, the third generation sensitizers can potentially be grafted with targeting moieties and may encapsulate imaging agents and then lead to the fourth generation of photosensitizers. Theranostic nanoparticles can be considered as which can diagnose, deliver targeted therapy and monitor the response to therapy.

Some key properties explain why nanoscale liposomes are an excellent material for targeted drug delivery (Barenholz, 2010) and the successful outcome of research using this approach, with the commercialization in November 1995, almost 17 years ago, of the first nanodrug developed on a liposomal platform, indicated for the treatment of cancer in gynecology. Many other nanodrugs have reached the market since, developed not only on liposomal platforms nor for treating cancers, such as verteporfin for injection, a product indicated for photodynamic therapy (PDT) in ophthalmology (Table 2).

What factors, different in nature but similar by analogy to the key pharmacological factors identified and pushed forward for nanoscale liposomes, are likely to make research on nano PDT a sustainable and successful approach in the development of targeted drug delivery material or systems for the treatment of cancer?

In order to try to indentify such factors and attempt to provide an answer to this question, we designed a case study to explore specific factors known to be crucial to risk management in complex settings involving multidisciplinary team work, complicated decision channels, fast-evolving highly technical new science and heightened uncertainty regarding potential risks but considerable potential human and financial benefits. We also designed a qualitative survey, to be conducted by questionnaire, addressed electronically to a selected population ranging from researchers specialized or not in the field of PDT to the educated social body, to investigate their perception of the research conducted in the field of Nanotechnology and Nanomedicine in general, and PDT in particular. The design of the case study is described in the next section, which starts with a presentation of the methodology used in constructing our interdisciplinary expertise, and the results of the pilot survey are analysed in section four.

Considering the growing interest of the research community in nanomedicine, on one hand, and the complexity of nano PDT, a highly specialized field of research that involves many sectors and multiple scientific disciplines, on the other hand, it is difficult, if not impossible, for each individual researcher involved to apprehend completely the risk management process, in its full scope. Thus, in this chapter, we would like to investigate this further by identifying interventions that could be applied here to facilitate and improve the intake of risk management in the researchers' preoccupation. In the course of the implementation of our interdisciplinary expertise, we have narrowed down the scope of our investigations to address exclusively, but in depth, three structured management interventions and modalities that have demonstrated their usefulness, which will be presented in the discussion (section five). 


\section{Design of the case study}

We start the description of the case study by introducing the method used and the literature that it is based on, before presenting the results of the pilot survey, in the following section (section 4).

\subsection{Method and literature review}

This interdisciplinary expertise was constructed using many iterative either bi or tridirectional exchanges which can be summarized in three broad steps, mixing both bottomup and top-down approaches, moving from a large to more narrow perspective, inward and/or outward centre bound:

1. Identification of the scientific object of the case-study and definition of its content.

2. Mutual understanding of the each author's potential contribution for integration: constrains, competencies and operational skills.

3. Implementation by iterative construction.

Starting from our respective knowledge base we first agreed on a common study object: the research on nano PDT conducted at the Reactions and Chemical Engineering Laboratory of the National Centre for Scientific Research ${ }^{10}$ located in Nancy. Although the experience was rejuvenating and stimulating, it entailed many challenged, some of which explain the limits of our work. The fact that the research on nano PDT involved other actors and ongoing scientific publications in a highly competitive field was a first obvious constrain that lead us to focus only on specific issues related to risk management. We also narrowed down the spectrum of our case study in order to obtain inputs from each individual of the multidisciplinary team: a photo-chemist conducting research in basic sciences and her post doctorate scholar, a risk management specialist and a public health medical specialist. We also expanded that spectrum, beyond a focus centred on individuals involved in that medical research domain, whether volunteers, patients or practitioners, in order to develop an interdisciplinary expertise open to large societal needs. Finally, among the many types of risks faced by research institutions, we concentrated mainly on internally driven hazard risk (i.e. health and safety issues), but also embraced, to a certain extend, both strategic and operational ones.

Beyond agreement on a common study object, a common understanding of each others' discipline was achieved in a progressive manner. Although the research on nano PDT conducted by some of us is at the foundation of our case study, our work also includes a qualitative survey. Our principal aim in doing so was to dispose of first hand and shared information regarding the state of knowledge of our study object in the general educated public.

We made an extensive use of the Information and Communication Technology (ICT), various software (Microsoft Work and Excel for instance) in particular to generate the various tables and figures, and of the Internet. We exchanged material (texts, tables, figures, articles) via e-mail all through the course of our work's development and used Google as a

${ }^{10}$ Laboratoire Réactions et Génie des Procédés (LRGP) du Centre National de Recherche Scientifique (CNRS) - France. 
tool to search for articles, retrieve full texts of certain publications and consulted various institutions' website for information relevant to our case study. We held only one whole team physical meeting, but had many 2 or 3 team members work sessions, either in Paris or Nancy, or by telephone.

The literature review does not present any particularity, in the sense that we used well known tools and methods, besides the fact that it was implemented in 2 specific and distinct steps. A specific bibliography is generated on Scopus and Medline, using various key words relevant to the research developed on nano PDT by some of the authors (PDT, nanoparticles, targeting, chemical grafting of fluorescent dyes, spectroscopy, interaction between light and living cells, etc). This is done on a regular base. Additional information is also added in an ongoing manner, during various continuing education operations such as scholarships, participation to national or international conferences and seminars or while tutoring postdoctoral students. Similarly, a steady expertise is withheld by some of the team members in risk management and public health policy applied to nanotechnology and other medical fields. Beside data banks such as those already mentioned (Scopus and Medline), Google Google scholar and Wikipedia are tools used on a regular base to keep abreast with knowledge development in the field of competencies. Update or skill development are also achieved using different continuing education media.

The originality of our interdisciplinary expertise lies more on the procedure that we implemented. Since no relevant unique bibliography could be screened and shared by all, and considering the solid knowledge base detained individually, we provided each other with selected articles or information. Once the common scope and general direction were determined, we conducted additional literature research (Scopus, Medline, Google Scholar) for articles and institutional publications to complement our development on health and safety issues in a risk management perspective. The precautionary principle and knowledge translation were the first two concepts that appeared relevant to investigate in our search for an answer to our study question in the particular context of research on nano PDT. We expanded later and more briefly on translational research, as this new management paradigm is distinct from the others and holds interesting features which can also facilitate the risk management process and emphasize the sustainability of the research field.

Today, working across sectors, fields and institutions is more and more frequent and slowly becoming the norm. However creating a common understanding of terms and concepts is difficult, because of the so many different linguistic styles. The limits of a purely disciplinary approach, which we consider improper to conduct relevant successful research in such complex fields, plead for interdisciplinarity in order to achieve a sound and robust risk management process.

In the following two sub-sections, we will describe and analyze successively the two elements that constitute our case study: the research on nano PDT which is at its foundation and the qualitative survey, a pilot survey which constitutes a common baseline of information.

\subsection{General framework of the case study}

The strategy implemented at the Reactions and Chemical Engineering Laboratory (LRGP) of the National Centre for Scientific Research (CNRS), in close collaboration with the 
Laboratory of Molecular Physical Chemistry (LCPM) and the Research Centre for Automatic Control - Centre Alexis Vautrin (CRAN-CAV), an anti cancer centre, both also located in Nancy, and the Physical Chemistry of Luminescent Materials Laboratory (LPCML), located in Lyon, consists in designing, characterizing and in vivo/in vitro testing new third and fourth generation photosensitizers to improve their selectivity for tumor vasculature and cells. So far, most of the endeavours in the development of tumor targeting-photosensitizers have focused on the targeting of markers over-expressed by tumor cells themselves, such as lectins (Distasio et al., 2005) or folic acid receptors (Gravier et al., 2008). Another promising strategy consisting in destroying endothelial cells lining angiogenic blood vessels may offer some advantages over the usual approach aimed at direct killing of tumor cells is also being developed. This vascular targeted PDT, designed by the acronym VTP for Vascular Targeted Photodynamic Therapy, could be proposed for a large number of vascularized tumors. Compared to conventional cancer cell-targeting approaches, targeting tumor vasculature is easier to access, more efficient in cancer cell killing, and has a lower likelihood of drug resistance development. This vascular effect can be potentiated either by modulating PDT scheduling or by designing photosensitizers that would localize primarily in the vascular compartment. For several years, the focus has been in developing photosensitizers coupled to vascular-targeting agents to target the neovasculature already formed (Tirand et al., 2006; Thomas et al., 2009). In order to improve PDT performance and more precisely the selectivity of the treatment, the potential of using nanoparticles is being investigated, particularly since 2008 (Bechet et al., 2008; Couleaud et al., 2010b), not only by the LRGP and its partners, but throughout Europe and in most of the OECD member countries.

Thus, starting from no publication prior to 1994, the number of publications on the development of nanoparticles for use in PDT has shown a sharp growth rate between 2002 and 2003 and is still increasing rapidly since 2006, reflecting the growing interest of the scientific community for the development of nano objects in the field of PDT (Figure 2).

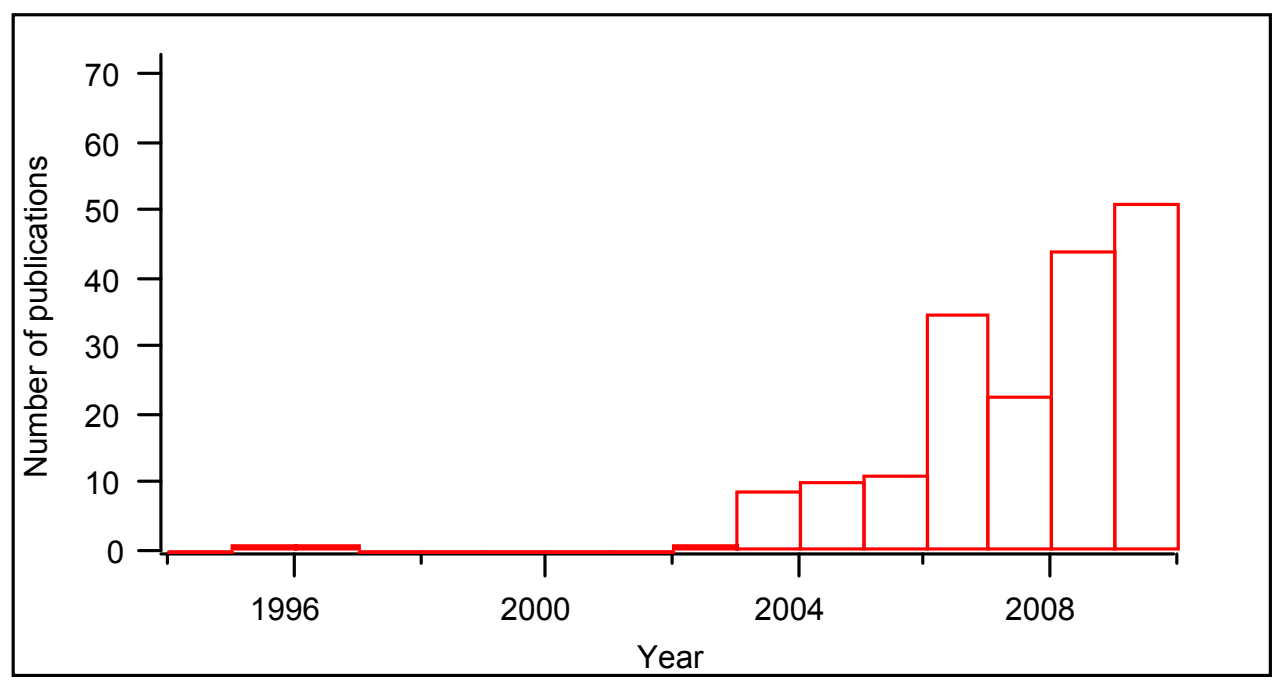

Fig. 2. Evolution of the number of publications on Photodynamic Therapy using nanoparticles from 1994 to 2010 (analysis from Scopus) 
The French nano PDT hub located in Nancy develops, in collaboration with its partner in Lyon, multifunctional silica nanoparticles (Couleaud et al., 2011). These non-biodegradable nanoparticles seem to be promised to a long lasting career, as they satisfy all the requirements for an ideal targeted PDT. For instance, Hybrid gadolinium oxide nanoparticles have been suggested to be useful for Magnetic Resonance Imaging (MRI), for both diagnosis and treatment (Faure et al., 2008). Their small size (less than 50 nanometer in diameter), their silica shell that allows the covalent coupling of a photosensitizer, their polyethylene glycol grafting, make them an ideal nanoplatform for both imaging and Vascular Targeted Photodynamic therapy (VTP). Inhalation of crystalline silica is known to cause an inflammatory reaction and chronic exposure leads to lung fibrosis and can progress into the disease, silicosis. The mechanism by which particles are bound and internalized and the reason why particles are toxic is unclear. Amorphous silica has been considered to be a less toxic form, but this view is controversial. In order to inhibit tissue accumulation of the nanoparticles, one way is to promote the urinary excretion of the nanoparticles. This can be accomplished by increasing the solubility of the nanoparticles. In the multifunctional silica nanoparticles developed by the Nancy Hub Research Team \& its partner in Lyon, polyethylene glycol grafting allows the covalent coupling of the peptide as well as a good solubility of the nanoparticles. By MRI in vivo in mice and ex vivo of the organs 24 hours post-intravenous injection, the elimination on the nanoparticles by renal excretion was demonstrated. More recently, the functionalization by peptides of such nanoparticle's photophysical properties as well as cytotoxicity and in vitro photodynamic efficiency, were also reported, describing for the first time the molecular affinity of the functionalized silica nanoparticle to neuropilin-1 molecular target (Couleaud et al., 2011).

Capitalizing on our respective past professional experiences and with the motivation to broaden our views for future developments, we have chosen to investigate some organizational issues that we consider crucial to take in account in order to forestall potential occupational, environmental and more broadly societal health risks emerging in the development of therapeutics using nanomaterials in PDT.

One of the main focuses leading our study is "research and sustainability", notably waste disposal, and, in this particular instance, the elimination of the nanoproduct, both from the body and in the environment. Thus, beyond the individual approach, the core of this work also concentrates on workers' safety, and to a certain extent, exposure of close contacts and community effects. Indeed, since laboratory practices, waste, as well as human subject excretion of nanomaterials can raise environmental concern, analysis of environmental effects should also be examined (Wolf and Jones, 2011).

\subsection{The pilot survey}

The decision to conduct a qualitative survey rose from the need to dispose of first hand and shared information regarding the level of knowledge of our specific study object, nanomedicine and more precisely PDT using nanoparticles, in the educated public. It was designed to be conducted by questionnaire, addressed electronically to a selected population ranging from researchers specialized or not in the field of PDT to the educated social body, to investigate their perception of the research conducted in the field of nanomedicine in general, PDT in particular, and the associated potential health hazards along with the means of protection. 
The questionnaire was elaborated with the intention to investigate different knowledge regarding medical research. A series of questions were organized in three sets that covered the following items:

- five short questions relating to general information on nanomedicine and the prerequisite specific to the initiation of a clinical trial;

- a broad and detailed table to fill, with the choice given to answer either yes, no or don't know, to the same questions regarding the different phases in the development of a new product in medical research; the following points were investigated: interdisciplinary team work in practice, knowledge of versus compliance to the existing regulation on health \& safety issues including their implementation in a cross sectoral and environment focused approach;

- two additional questions pertaining to the special field of clinical research, regarding the transition from experiments on animals to trials in human and the implementation of the principle of the necessary informed consent of the participants.

The target population was selected to cover an audience educated enough to be aware of the specific research field represented by nanomedicine. We initially aimed at two distinct groups: the general social body with approximately a master's level of education, investigated via Non Governmental Organisations (NGOs), and a population of researchers, either practising or still in training.

Four institutions were selected ${ }^{11}$ :

1. the "Académie Lorraine des Sciences", a professional body with a total of approximately 300 members from multiple scientific backgrounds;

2. the "INstitut des Sciences de l'Ingénierie et des Systémes (INSIS)", one of the CNRS's major actor of research acting in engineering sciences and covering roughly 10000 persons working in more than 150 laboratories all over the country;

3. "Poursuivre";

4. the "Association de Veille et d'Information Civique sur les Enjeux des Nanosciences et des Nanotechnologies (AVICENN)".

We were provided with feedback from only the latter.

The questionnaire was sent via e-mail to a representative of each institution, previously contacted, informed and sensitized of the strict deadline. Distribution was agreed to rest upon an intermediate within each of the selected institution, using internal mailing lists and the filled questionnaires were to be returned directly to the organizing team. A three weeks for response delay, going from June $10^{\text {th }}$ to $30^{\text {th }}$ 2011, was initially proposed to the participants, but the very low response rate in the course of implementation led to telephone contact with our correspondents and an additional five days bonus. The following biases were then identified:

\footnotetext{
${ }^{11}$ The "Académie Lorraine des Sciences" (Academy for Science of the Lorraine Region) is a local regional institution, and the two NGO's, "Poursuivre" and AVICENN (Surveillance and civic information on issues related to nanoscience and nanotechnology) have a national scope and audience.
} 
- the institutions had transferred the questionnaire on a hierarchical mode, and, in most cases, the responsible had delegated the answer to the individual in their team they judged the most competent on the central theme of our survey;

- similarly, and in particular in the case of the NGOs, our correspondents informed us that their activities being extremely far from the subject of PDT, they did not feel legitimate to answer the questionnaire.

Although the total number of individual who actually received the questionnaire to fill is unclear, the response rate, with 21 questionnaires returned filled, among which 14 from the Nancy hub, was obviously certainly very low. This observation is particularly striking for the intended investigation of the general social body, as only one representative of AVICENN, identified as the focal point by the institution, provided us with one duly completed and extensively commented questionnaire that reflected the NGO's standpoint.

\section{Results of the pilot survey}

In fact, the questionnaire covers a wide sample of disciplinary and applied scientific fields: research, Research and Development (R\&D), experiments on animals and clinical research in human, doctor-patient relationship, ethical and regulatory issues relating to social responsibility, etc. It was conceived to collect first hand and shared information on the competencies of different actors or social groups on our specific field of study: photodynamic therapy using nanoparticles in cancer therapy. The previously described limitations and biases, notably in the recruitment of the target population (screening and casting), make our pilot survey totally unsuited to be representative of the expression of an educated population's opinion, but still useful for our initial and immediate purpose. Moreover, this could also be an interesting preliminary and very instructive phase to determine feasibility of a similar survey on a larger scale.

In summary, our survey, implemented from June $10^{\text {th }}$ to July $5^{\text {th }} 2011$, provided note worthy elements of information that served our need to better situate the use of nanoparticles in PDT as a field of relevant clinical research.

1. Respondents are rather competent on the central theme, master quite well the clinical medical issues, and in particular the classical known difficulties specific to moving from research to the application of the results in current practice (i.e. knowledge translation and translational research).

2. Association between creativity and interdisciplinary approach is subject to a real debate, partly due to lack in fruitful interactions between the many scientific fields and insufficient funding; however, when existing, the interdisciplinary mode of action is centred on the specific application, without an analysis of the related other aspects (i.e. health and safety issues, risk prevention, regulatory and ethical considerations).

3. Precautionary approach indispensable to conducting clinical research seems completely unknown, in particular the health \& safety issues specific to each of the phases in a product's development starting from basic research is not the object of much attention from the various categories of responding professionals (researchers, technicians, maintenance, transport and cleaning personals). The discourse refers only to the existence of regulation without explicit mention of risk management in this context of 
uncertainties; the precautionary principle for instance is not highlighted and priority seems to be given "only" to the scientific production attached to research. This comment does not apply to the answer provided by AVICENN, since the organisation is grounded on a social mission to inform on the risks related to nanosciences and nanotechnology, and feeds its legitimacy on the surveillance of their applications, thus on short and long term effects in human and the environment.

4. As a whole, risks identified are centred on those incurred by patients who are concerned with the intake of nanodrugs in clinical research, and in particular bioaccumulation, while hazards which may occur in hospital personnel who attend their needs are not mentioned. The same observation applies when it comes to the elimination of those substances which may cause damage to the environment, and the waste generated is not the object of expressed concern. Hence, life cycle analysis is an element that should be induced in the various professional's preoccupations.

5. Doctor-patient relationship in their interactions is well described, as well the role of the doctor in relation to his patients.

6. Interesting comments are made regarding commercialisation of new products after approval by the relevant authorities, but they are situated outside of the scope of our pilot project. They probably translate a context effect with the present debate occurring in France.

Concerning specifically health and safety preventive measures at the workplace and the question investigating knowledge of versus compliance to them, besides the fact that in most instance $(70 \%)$ respondents either declared a lack of knowledge or did not pronounce themselves outside of their own area of practice, some interesting remarks made can be highlighted and commented:

1. The absence of a real culture of prevention in university settings, probably related to the absence of control by the relevant authority, along with a pressure to deliver immediately, which contrasts with the industrial world where risk prevention is rigorously handled, apart probably within subcontracting companies.

2. The need to upgrade the health and safety equipment and installations in the universities to render them appropriate to safe working conditions, leading responsible management to use some of their project funding toward this end, an honourable decision but nevertheless a form of misappropriation of funds.

3. The question of the information of the personnel, and more broadly of the citizens vis à vis the traditional dialectic of a priori criticism of the precautionary principle is raised. Viewed as a bridle to innovation and the freedom of entrepreneurship by some, the application of the precautionary principle can be an interesting economic and social development tool to avoid health crisis, such as the asbestosis one which negative effects are well known today. Moreover, it can sustain the public's demand of an As Low As Reasonably Achievable (ALARA) type of leadership (Manigat et al., 2010).

4. The notion of independence of the experts in general, and of the scientists in particular, when conducting safety studies, imperious in order for the results to be delivered without pressure to major or minor risks, pleading for funding from independent institutions.

However, no conclusion in term of weight of the above mentioned remarks and comments can be reasonably made, as a good amount of respondents $(30 \%)$ reported difficulty in 
understanding the questions that they qualified either unclear or expressed in a too complicated format, and skipped the question. Among those, around 50\% expressed their reasons, which can be summarized by the following two explanations: the questionnaire was too long and the time announced to fill it was inadequate, and, the fields investigated were too broad and too distant from their own work environment.

\section{Discussion}

Whether political, administrative, legal, industrial, scientific or technical, public or private, any kind of organisation claims legitimately to aim at meeting their immediate, intermediate or long-term, more distant objectives. The key element for success is obviously a realistic planning were objectives are set taking in account the required material and human resources. Whether internally or externally driven, four types of generic risks can threaten the achievement of the goals and objective of an organisation: financial, operational, strategic and hazards (IRM, 2002).

Risk management, which can be defined as the set of individual or institutional response to the analysis and assessment of risks, including decisions to reduce or control risks (Ebbesen and Jensen, 2006), covers distinct realities according to the area involved (enterprise, industry, project, technology etc.). However, diverse initiatives have successfully conducted to a comprehensive approach and an internationally recognized level of standardization ${ }^{12}$. Risk management protects and adds value to the organisation and its stakeholders through supporting the organisation's objectives by different means, and notably: i) providing a framework that enables future activity to take place in a consistent and controlled manner, ii) improving decision making, planning and prioritisation, including in the allocation of material and human resources, iii) reducing volatility in the non essential areas, iv) protecting and enhancing assets and the organization's image, v) developing and supporting the knowledge base, and, optimizing operational efficiency (IRM, 2002).

Risk treatment, inclusive of the risk management process (Figure 3), comprises risk control/mitigation as its major element, but extends further to risk avoidance, risk transfer, risk financing etc. However, the standard states specifically that compliance with laws and regulations is not an option.

In the following three sub-sections, we will discuss concepts that we believe useful to take in account in order to improve the risk management process, in general, and the quality of our work, in particular. The precautionary principle and knowledge translation will be highlighted first and extensively, as they immediately appeared relevant to investigate in our search for an answer to our study question. We will also expand on translational research, as this new management paradigm, distinct from the others, also holds interesting features which can contribute to make research on nano PDT a sustainable and successful approach in the development of targeted drug delivery material or systems for the treatment of cancer.

\footnotetext{
12 ISO/IEC Guide 73:2009. Risk management - Vocabulary, and, ISO/DIS 31000 (2009). Risk management - principles and guidelines on implementation, among others.
} 


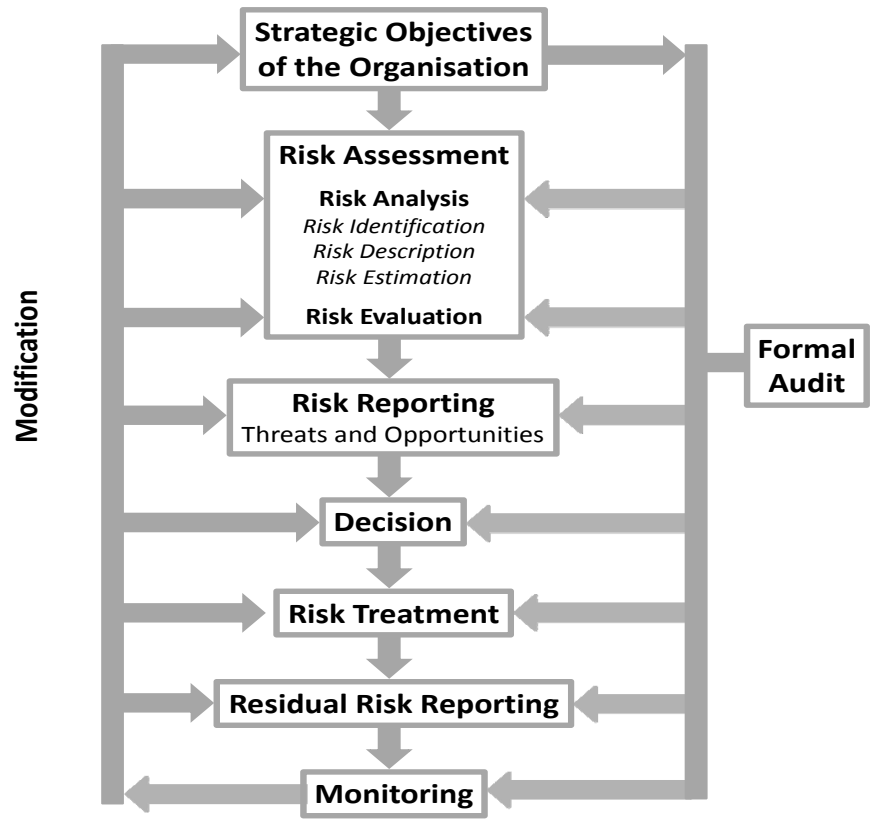

Fig. 3. The Risk Management Process (IRM, 2002)

\subsection{The precautionary principle}

Like scientists, who include elements of caution in the course of the assessment of scientific data, decision-makers are faced with similar issues, and can rely on the precautionary principle in a structured approach to risk management when shaping, accenting then releasing their decision. Although the two processes do resemble, they differ in the sense that the recourse to the precautionary principle is a particularly relevant strategy to the management of risk when potential dangerous and irreversible effects have been identified, but their scientific estimation holds a certain level of uncertainty. The decisions made using this strategic option can take many forms and does not necessarily have to be a binding legal measure. However, it should be transparent and involve, as early as possible and to a reasonable extent, all interested parties (CEC, 2000). In that respect, the recourse to public consultations, a practice that the Information and Communication Technology (ICT) has considerably facilitated, is spreading rapidly, and in particular within the European Commission.

In France, the principle was introduced in the country's legal regulation by the law related to the reinforcement of the environment's protection dated February 2nd 1995, often referred to as "la Loi Barnier", which expresses the way to explore systems where risks are not mastered. Hence, in its article L200-1, the Rural Code stipulates: The precautionary principle, according to which the absence of certainty, given the state of scientific and technical knowledge, should not delay the adoption of effective and proportionate measures to prevent a risk of serious and irreversible environmental damage at an economically 
acceptable cost. When applied, it is clearly a means to manage uncertainties and in no way a means of abstention. This new framework developed to implement action is of particular relevance in our contemporary world where innovation is intensively generated, as it leaves room to adapt to change.

At the supra national level, the most recent consensus rely on the February 2000 Communication from the Commission (CEC, 2000), in which all of the major components of the precautionary principle agreed on are specified, and in particular the need for decision makers to be aware of uncertainty attached to the result of the evaluation of the available scientific information and the eminently political responsibility for judging what is an acceptable level of risk for society. Gaps in knowledge and scientific uncertainty highlighted after the evaluation of a potential hazard are among the triggering factors that can lead to the recourse to the precautionary principle.

It is important to point that the general concept of risk management is quite similar to the precautionary principle, although it applies to a context of a more established certainty. The recourse to the precautionary principle, particularly relevant when facing a severe and irreversible potential hazard, can intervene after the risk assessment sequence of the risk management process.

The implementation of the precautionary principle in medical research and public health also calls to revisit the current causal inference methodologies (Kopelman et al., 2004; Weed, 2004) and to refocus on many fundamental ethical principles and values (Jardine et al., 2003). The principle is of extensive use also in the USA and Canada, by both Governments and Non Governmental Organizations, professional bodies, and the civil society, as illustrated by the following examples: the Canadian Environmental Act 1999 that came into force on March 31st 2000; the introduction of the precautionary principle by New York State and San Francisco City \& County in their respective regulations in March 2003; the Wingspread Statement on the Precautionary Principle released by a group of scientists, philosophers, lawyers and environmental activists on January 20th 1998 to resume after a three days conference; or the American Public Health Association's resolution on the Precautionary Principle and Children's Health dated November 15th 2000.

Therefore, crucial to the theme of our work, our subsequent development will be centred on management and organizational modalities that have rendered their usefulness: knowledge translation and translational research.

\subsection{Knowledge translation}

Lack of knowledge, whether poor level of information or apparent inadequate use of knowledge regarding health and safety at the work place, regardless of the product in development's stage and environment (i.e. type of laboratory), was mentioned in a good proportion of the educated populations' responses to our questionnaire. Thus, considering the main characteristics attached to the subject of nanodrugs for PDT in cancer therapy ${ }^{13}$, it

\footnotetext{
${ }^{13}$ One of the most rapidly growing branch of science and fairly new field of research - nanomedicine but using an old but not frequently applied technology - PDT, numerous actors and stake holders involved, real controversies debated on health risks with sister technologies like carbon nanotubes, incredible economical weight voiced by industrials as to potential benefits challenged by NGO's as to
} 
seems more than relevant, in today's health economic-aware environment, to question the knowledge translation process which provides scientific methods for closing the knowledge to action gap and identify the inherent barriers and facilitators (Straus et al., 2009a).

Knowledge translation is defined as a dynamic and iterative process that includes synthesis, dissemination, exchange and ethically-sound application of knowledge to accelerate the capture of the benefits of research through improved health, more effective services and products, and to strengthen the health care system. This process takes place within a complex system of interactions among researchers and users that may vary in intensity, complexity and level of engagement depending on the nature of the research and the findings as well as the needs of the particular knowledge user (CIHR, 2004).

We adopted the knowledge to action process developed in Canada, as the guiding overarching framework to identify potential areas of possible usefulness for the improvement of such an intervention (Figure 4).

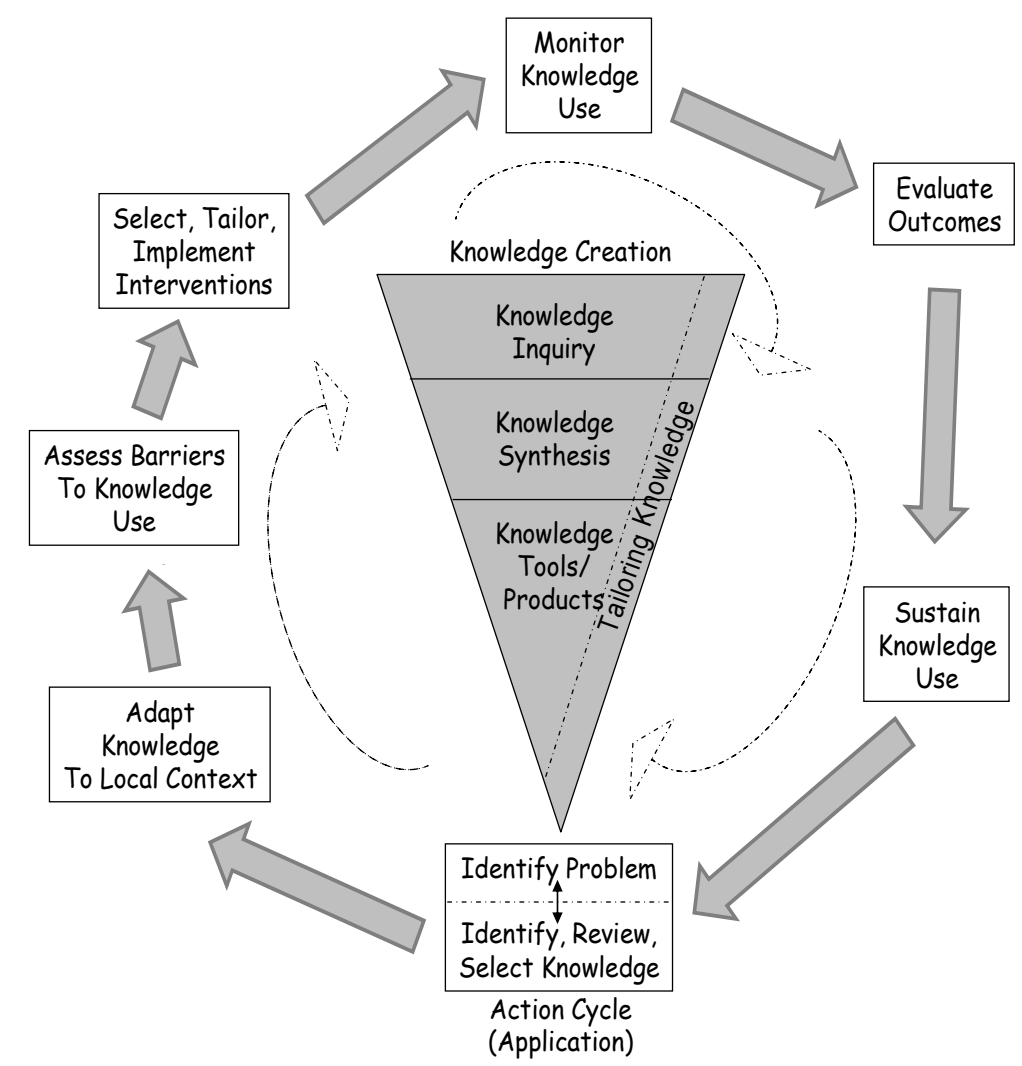

Fig. 4. Knowledge to action process (Graham et al., 2006)

long term potential effects detrimental to man, endless amount of available information, huge already existing market applications and developments. 
In the course of the knowledge translation process development, whether during the creating or applying phases, some steps are more prone than others to allow identification of knowledge to action gaps, barriers or facilitators, which, when assessed at an early stage, can successfully lead to find suitable solutions. Considering the knowledge issues commonly identified in health and security studies, and also observed in the results of our pilot survey, it is worth stressing that knowledge needs and knowledge use should be the object of special focus, and carefully addressed.

The identification of knowledge to action gaps can occur anytime throughout the course of the knowledge translation development, either when refining distilling and tailoring knowledge to the needs of end-users during the knowledge funnel (i.e. inquiry, synthesis, and generation of user friendly knowledge tools and products), or when applying knowledge during the action cycle while assessing barriers \& facilitators to knowledge use or developing mechanisms to sustain ongoing knowledge use (Straus et al., 2009a).

It has been established that gaps between research and practice may result from interacting factors such as limited time and resources of practitioners, insufficient training, lack of feedback and incentives for use of evidence-based practices, inadequate infrastructure and systems organisation to support translation. More recently, the assumption that effectiveness research (intended to measure the impact of an intervention on the target population) naturally and logically follows from successful efficacy research (which purpose is to establish a causal link between and intervention and its outcome), has been challenged in health promotion research, leading to highlighting a disconnection inherent to their very distinct designs and purposes. The moderating factors, that limit robustness across settings, populations, and interventions staff, need to be addresses in efficacy studies (Glasgow et al., 2003).

To sum up, we want to highlight the following remarks:

1. Underuse or overuse of evidence with critical impacts have often been reported, making monitoring of knowledge use a fundamental issue, considering the different types that may be involved; the appropriate method to close or lessen gaps in knowledge use will vary whether dealing with conceptual (to change the levels of knowledge, understanding and attitudes), instrumental (to change behaviour or practice) or strategic (as ammunition in the attainment of power or profit) knowledge use (Straus et al., 2009a; Manigat et al., 2010).

2. Assessing barriers and facilitators to the implementation of shared decision making is crucial, since barriers and facilitators are the salient beliefs of self efficacy, the most important determinant of behavior change after intention, on one hand, and, considering the fact that a given factor can be perceived as both a barrier or a facilitator, on the other hand (Straus et al., 2009a).

3. Interest in sustainability of knowledge use is quite recent (Graham et al., 2006), nevertheless, the consideration of sustainability, which includes discussion of budgetary and human resources, should occur early in the process (Straus et al., 2009a).

4. Lack of knowledge, also identified in our survey concerning health and security issues, is, with variability, one of the two generic sources of uncertainty; it can be either structural or due to unreliability, and in that second instance potentially measurable (Van Asset, 2000, as cited by Hoppe, 2009; Van Asset et al., 2002). 
5. Uncertainty in knowledge is now an established triggering factor for the application of the precautionary principle (CEC, 2000).

6. When people are given more freedom to get involved, they more actively engage in finding creative solutions to routine problems and implementing them (Straus et al., 2009a).

Ultimately, and consistent with the vision for knowledge management promoted by the Canadian Institute of Health Research (CIHR), the development of a systematic, integrated approach to accelerate optimal use of the best available research evidence in the interest of health would be particularly useful here. Furthermore, as often reported and also evidenced in the analysis of the information retrieved in our survey, it appears that a real margin of improvement does exists, since gaps in knowledge remain in the course of the implementation in highly interdisciplinary research in nanomedicine. The four comments aforementioned concerning specifically health and security preventive measures at the workplace are valid beyond biomedical research and the field of nanomedicine. Pushed forward with the recent controversies, still ongoing, regarding nanosciences and nanotechnology, they unfortunately reflect the general "traditional" and prevailing situation which critically calls for reconsideration. A deep reflexion could be advantageously developed, centred on the following: a reasoned exploration for the frame of application of the precautionary principle for nanodrugs and nanomedicine; communication on the innovations in the field; the interrelations between the product and technique conceivers and users; and, in order to prevent potential environmental hazards, the life cycle analysis, the development of research on processes to eliminate waste or recycle the material.

\subsection{Translational research}

Translational Research also aims to bring health information and discoveries to the public to improve well being and health. Although, the term may mean different things to different people, it was initially described as comprised of two areas of translation (Figure 6): the process of applying discoveries generated during research in the laboratory and in preclinical studies to the development of trials and studies in humans and vice versa - or from bench to bedside and back (T1 translation), on one hand, and, research aimed at enhancing the adoption of best practice in the community and back - or from research into practice (T2 translation). Two additional translations were later identified to better reflect the complexity of the second component of the translational research paradigm: moving research finding into the daily care of patients (T3), and moving scientific knowledge into the public sector and thereby changing people's everyday life (T4) (Woolf, 2008; Kon, 2008).

Improving the funding balance within translational research, between "bench to bedside (T1)" and "research into practice (T2)", the latter often overshadowed by the primer notably in the United States, was shown to be crucial at a time when experts warn of the fragmented health care system and the huge disparities in access and quality of care. Poverty matters as much as proteomics in understanding disease, even though the scientific discoveries and spectacular new devices are more fascinating to the public and more lucrative to the industry. Additionally, for many diseases, T2 could save more lives than T1 as, for example, greater fidelity in administering aspirin to eligible patients might prevent more strokes than developing more potent antiplatelet agents (Woolf, 2008). Under this translational research paradigm, (i.e. avoiding to neglect historically less 
glamorous components than bench research which are prone to dramatically improve public health and decrease cost), there will be more funding and consequently more recognition for such work (Kon, 2008).

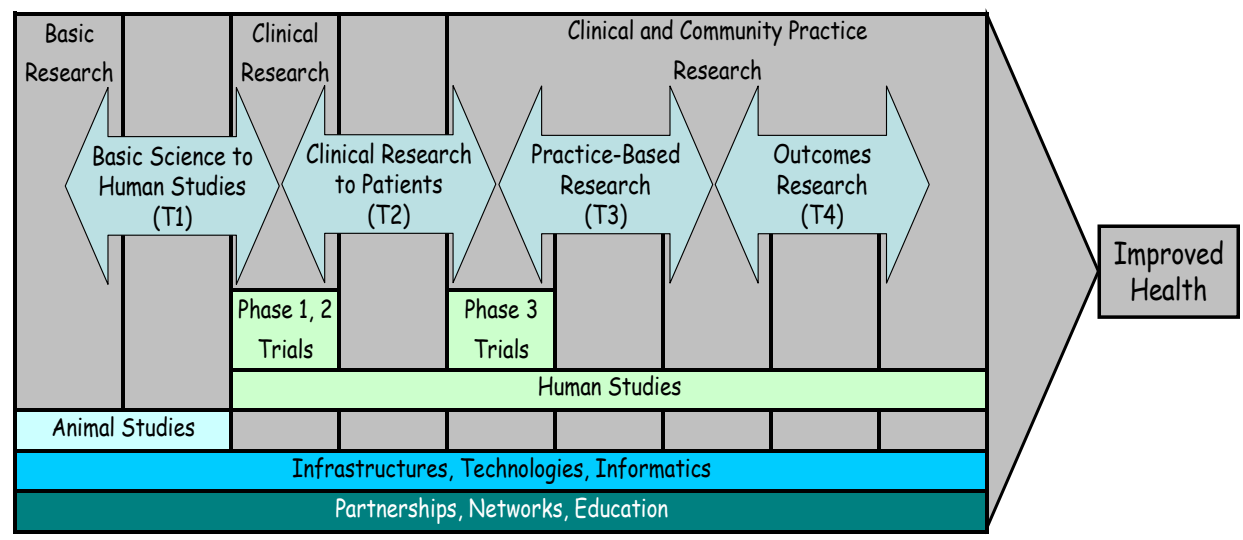

Fig. 5. The Continuum of Biomedical Research (UTSUMC, 2011)

The research on PDT using nanoparticles developed at the Reactions and Chemical Engineering Laboratory of the National Centre for Scientific Research is also implemented within a network of laboratories and could benefit from implementing the concept.

\section{Closure and future work}

Building on the study of 14 past cases, drawn as far as in 1896, related to hazards that caused damage to humans and the environment and for which early warnings where available, the European Environmental Agency (EEA, 2001) produced a report that illustrates the relevance of the precautionary principle's implementation. The following twelve late lessons learnt where highlighted from this historical analysis:

1. Acknowledge and respond to ignorance, as well as uncertainty and risk, in technology appraisal and policy-making.

2. Provide adequate long term environmental and health monitoring and research into early warnings.

3. Identify and work to reduce blind spots and gaps in scientific knowledge.

4. Identify and reduce interdisciplinary obstacles to learning.

5. Ensure that real world conditions are adequately accounted for in regulatory appraisal.

6. Systematically scrutinize the claimed justifications and benefits alongside the potential risks.

7. Evaluate a range of alternative options for meeting needs alongside the option under appraisal, and promote more robust, diverse and adaptable technologies so as to minimize the costs of surprises and maximise the benefits of innovation.

8. Ensure use of lay and local knowledge as well as relevant specialist expertise in the appraisal. 
9. Take full account of the assumptions and values of different groups.

10. Maintain the regulatory independence of interested parties while retaining an inclusive approach to information and opinion gathering.

11. Identify and reduce institutional obstacles to learning and action.

12. Avoid paralysis by analysis by acting to reduce potential harm when there is reasonable ground for concern.

They all appear relevant to be taken in account in our subject of study with two central themes also quite consistent with the conclusive analysis of our pilot survey: knowledge issues in a scientific field were risks are identified but not yet fully evaluated thus withholding uncertainties, and, obstacles to learning in interdisciplinary settings.

The heightened possible risks widely described for certain nanomaterials in recent publications (Poland et al., 2008; Takagi et al., 2008; Genaidy et al., 2009; Murphy et al., 2011), the multiple sources of uncertainty, either primary due to variability or secondary in relation to limited knowledge, the absence of a robust common and universally accepted terminology, the ongoing debates to agree on appropriate regulation, are so many reasons that makes it legitimate to refer to the precautionary principles in the course of the decision making process when dealing with particles, materials and devices in nanomedicine.

Knowledge management is crucial, so referring to knowledge translation should also carefully be considered in that context of uncertainties and controversial points of view, where knowledge gaps are definitely known to exist. The systematic and full use of the knowledge to action process, funnel and action cycle, may offer a model on which research institutions should consider relying, either for internal evaluation (e.g. when monitoring knowledge use) or during external audits (e.g. for evaluation of outcomes). Although sustaining knowledge use appears as the last of the 7 steps in the action cycle (Figure 5), consideration of sustainability, which include discussion on budgetary and human resources, should occurs early in the process (Straus et al., 2009a).

However, awareness should exist on the fact that a successful implementation of knowledge translation is also a daunting task, considering the challenges to be faced, and in particular the lack of knowledge management and infrastructure, such as the huge volume of research evidence currently produced, access to research evidence, time to read and skills to appraise, understand and apply research evidence. Other challenges identified operate at many other different levels, including the health care system (e.g. financial disincentives), the health care organization (e.g. lack of equipment or personnel), the health care teams and individual professional, and also the patient (Straus et al., 2009b). Although the strategy may not have been extensively studied in the health care research sector, the use of either information specialists (Wilkinson et al., 2009) or knowledge brokering (Oldham and McLean, 1997; Lomas, 2007; Dobbins et al., 2009), as seen in clinical nursing practice (Kent et al., 2009), could be an interesting strategy to implement after further proper assessment of possible added value, in order to enhance knowledge translation.

Since, when people are given more freedom to get involved, they more actively engage in finding creative solutions to routine problems and implementing them (Straus et al., 2009a), management style is also important and the stewardship theory of management, developed as a counter strategy to agency theory in 1997 (Olson, 2008), should be explored. Beyond the afore mentioned need for a relevant level of material and human resources, indeed the five 
components of the management philosophy of the stewardship theory of management (i.e. performance enhancement, long-term orientation, empowerment, open communication \& trusting relationship) could be inspiring to reduce interdisciplinary obstacles to learning as well as institutional obstacles to learning and action.

Although risk management is increasingly recognized as being concerned with both positive and negative aspects of risks, in the safety field, risk management's focus should be on prevention and mitigation of harm, as it is generally recognized that in that given field, consequences are only negative (IRM, 2002). Compared to research in techno-sciences, scientists who initiate research in the biomedical field have obviously integrated ethical issues in their processes (Couleaud et al., 2010a). Among the explanations, we retain the consequences of some major health crisis such as the use of thalidomide and the cancer of the uterus later induced in the offspring or the asbestos induced mesothelioma in factory or construction industry workers. Today, risk analysis seems inclusive of the culture of most medical scientists.

The ethical considerations to take in account when addressing some technologies developed for applications in nanomedicine have been examined, notably for nanosurgery, tissue engineering, diagnostics and targeted drug delivery (Ebbesen and Jensen, 2006). Although ethical considerations to take in account when developing research in the field of nanomedicine are more complex, the knowledge base acquired in the field of bioethics seems sound enough, and the recourse to the four principles of Beauchamp and Childress' theory - doing Good (Beneficence), avoiding harm (Non-Maleficience), respect of autonomy (Autonomy Protection) and justice (Protection of Equity/Justice) - a set of values commonly used today in ethical analyses (Ebbesen and Jensen, 2006; Westerholm, 2010), something to build on. The increasing weight of cancer in the global mortality and morbidity legitimates to search for new drugs and the discovery of new modes of treatment. However, research protocols applied on vulnerable populations have also obvious ethical limitations and also call for a thorough oversight. The need for interdisciplinary research on the ethical, legal and social implication of nanomedicine and enhanced information exchange, particularly on toxicity studies and informed consent procedure with regard to safety, has been underlined by the European Group on Ethics in Science and New Technologies to the European Commission (EGESNT/EC, 2007). The group has also argued that as far as public participation is concerned, transparency, including openness about uncertainties and knowledge gaps, is essential to ensure public trust in nanotechnology. Moreover, the group has stressed that in prospective technology assessment, consideration of social effects should expand to the developing countries. Indeed we agree, as we believe in global adaptation of new technologies to the human species and not in the reverse paradigm (Manigat et al., 2010). A large interdisciplinary scientific debate has to be opened to agree on boundaries and limits, notably to human enhancement, include the decision makers to set strategic orientations and expand to the civil society.

While ethical considerations should have always been consubstantial with the practice of medicine (Hippocrates's Oath, Code of deontology), the need for legislative measures has emerged partly with the growing complexity of medical practice and research in humans, and probably more strongly with the history of past events such as the Tuskegee syphilis experiment in the US (Emanuel and Menikoff, 2011). The urge to adapt the legal framework to the challenges of nanomedicine, maybe even on a regular base, is real, and the debate on 
the most appropriate reform is an ongoing process in the USA as well as in France and within the European Commission Member States. The call for the development of mandatory nanospecific regulation seems highly legitimate since most existing laws and regulations focus on cleaning up and controlling damage rather than preventing it ${ }^{14}$, and is consistent with the claim from the industrials that nanotechnologies are novel technologies. Since the risk management process clearly specifies that compliance with the laws and regulations is not an option, needless to stress that the rules must be carefully conceived in order to be also applicable, and achieving that could be a daunting and lengthy process.

Additionally, monitoring of the insurance industry's policies is worth investigating and can provide useful inputs, as risk treatment can be dealt with using risk financing and insurers do not manage risk coverage haphazardly.

The implementation of this interdisciplinary expertise was a unique experience from which we can highlight the following elements as key messages:

- The limits of a purely disciplinary approach, which we consider improper to conduct relevant successful research in such complex fields, considering the multiplicity of the knowledge gaps and other issues that are at stake and jeopardize a sound risk management process.

- Although the pilot survey was developed for a precise and limited purpose, it could serve as the first step - the feasibility phase - of a qualitative study for a larger research project, if proper funding can be obtained.

- Lessons learnt from the precautionary principle, applied in risk management of many other instances, could be food for though in the development of nano PDT as a relevant and sustainable research field in medicine.

- Translational research, another new management paradigm, should also be explored.

- Other recommendations are expressed (e.g. the use of information specialists or knowledge brokering, the shift to a stewardship style of management), addressed to the decision makers, and it is up to the relevant authority to decide whether or not they want to implement them.

- Moreover, future work can also usefully be conducted, oriented in the two following sectoral directions that represent real openings: ethical and regulatory issues.

"One hopes that our society will be able to muster the collective financial and moral courage to allow such extraordinarily powerful medicine to be deployed for human betterment, with due regard to essential ethical considerations." Robert Freitas

\section{Acknowledgements}

We want to thank the following individuals and institutions for their support in the implementation of this work: Muriel Barberi-Heyob (Nancy Hub Research Team), Roger

\footnotetext{
${ }^{14}$ The whole rational, published on the Science \& Environmental Health Network, relates to the aforementioned Wingspread Statement on the Precautionary Principle released by a group of scientists, philosophers, lawyers and environmental activists on January 20 th 1998 to resume after a three days conference (Wingspread Conference on the Precautionary Principle. Available from:

http://www.sehn.org/wing.html).
} 
Salamon (President of the High Council on Public Health), Renée Pomarède (Ministère du travail, de l'emploi et de la santé); important partners in the pilot survey who helped us for the dissemination of the questionnaires: the non governmental organisation AVICENN (Association de Veille et d'Information Civique sur les Enjeux des Nanosciences et des Nanotechnologies) and the National Centre for Scientific Research's institute INSIS (INstitut des Sciences de l'Ingénierie et des Systémes); and Helène Leyland for her invaluable last minute inputs.

\section{References}

Agence Française de Sécurité Sanitaire de l'Environnement et du travail (AFSSET). (July 2006). Les nanomatériaux. Effets sur la santé de l'homme et sur l'environnement, AFSSET, France. Last consulted on August 30 th 2011. Available from: http://www.afsset.fr/upload/bibliotheque/367611898456453755693572842048/na nomateriaux.pdf

Agence Française de Sécurité Sanitaire de l'Environnement et du travail (AFSSET). (July 2008). Les nanomatériaux. Sécurité au travail, AFSSET, France. Last consulted on August 30th 2011. Available from:

http://www.afsset.fr/upload/bibliotheque/258113599692706655310496991596/afs set-nanomateriaux-2-avis-rapport-annexes-vdef.pdf

Agostinis, P.; Berg, K.; Cengel, K.A.; Foster, T.H.; Girotti, A.W.; Gollnick, S.O.; Hahn, S.M.; Hamlin, M.R.; Juzeniene, A.; Kessel, D.; Korbelik, M.; Moan, J.; Mroz, P.; Nowis, D.; Piette, J.; Wilson, B.C. \& Golab, J. (2011). Photodynamic therapy of cancer: An update, CancerJournal of Clinicians, 61, 250-281

André, J.C. (2008). Vers le développement d'une recherche durable... ou vers une (ré)humanisation des sciences des artefacts, Environnement, Risques et Santé, 7 , 47-54

Barenholz, YC. (2010). Targeted Nanodrugs: The Drugs of the 21 st century? Science, Technology, and Commercialization Venues. Lecture made on February 9th 2010 at the $6^{\text {th }}$ Workshop, The Center for Nanoscience \& Nanotechnology, Tel Aviv University, February 9-11, 2010, Maalot. Last consulted on August 30 2011. Available from Available from: http:/ / www.youtube.com/watch?v=7pvQxL2UnKY

Bechet, D.; Couleaud, P.; Frochot, C.; Viriot, M.L. \& Barberi-Heyob, M. (2008). Nanoparticles for photodynamic therapy agent delivery, Trends in Biotechnology, 26, 612-621

Canadian Institute of Health Research (CIHR). (2004). Knowledge translation strategy 20042009. Innovation in action. Last consulted on August 30th 2011. Available from: http://www.cihr-irsc.gc.ca/e/26574.html

Chen, B.; Pogue, B.W.; Hoopes, P.J. \& Hasan, T. (2006). Vascular and cellular targeting for photodynamic therapy. Critical Reviews in Eukaryotic Gene Expression;16(4):279-305

Commission of the European Communities (CEC). (2000). Communication from the Commission on the precautionary principle. Brussels, Belgium. Last consulted on August 30th 2011. Available from:

http:/ /ec.europa.eu/dgs/health_consumer/library/pub/pub07_en.pdf

Couleaud, P.; Faure, M.; Verhille, M.; Manigat, R. \& André, J.C. (2010a). From public to occupational health: towards an inverse push-pull paradigm in nanotechnologies innovation, G. Ital. Med. Lav. Erg. 32:4, 400-402

Couleaud, P.; Morosini, V.; Frochot, C.; Richeter, S.; Raehm, L. \& Durand, J.O. (2010b). Silica-based nanoparticles for photodynamic therapy applications. Nanoscale, 2, (7), 1083-1095 
Couleaud, P.; Bechet, D.; Vanderesse, R.; Barberi-Heyob, M.; Faure, A.C.; Roux, S.; Tillement, O.; Porhel, S.; Guillemin, F. \& Frochot, C. (2011). Functionalized silica-based nanoparticles for photodynamic therapy, Nanomedecine, under press

Department of Health and Human Services/Centers for Disease Control and Prevention/National Institute for Occupational Safety and Health (DHHS-CDCNIOSH). (2009). Approaches to safe Nanotechnology: Managing the Health and Safety concern Associated with Engineered Nanomaterials. Publication $N^{\circ} 2009$ 125. Last consulted on August 30 th 2011. Available from: http://www.cdc.gov/niosh/docs/2009-125/pdfs/2009-125.pdf

Di Stasio, B.; Frochot, C.; Dumas, D.; Even, P.; Zwier, J.; Müller, A.; Didelon, D.; Guillemin, F.; Viriot, M.L. \& Barberi-Heyob, M. (2005). The 2-aminoglucosamide motif improves cellular uptake and photodynamic activity of tetraphenyl porphyrin, European Journal of Medical Chemistry, 40, 1111-1122

Dobbins, M.; Robeson, P.; Ciliska, D.; Hana, S.; Cameron, R.; O’Mara, L.; DeCorby, K. \& Mercer, S. (2009). A description of a knowledge broker role implemented as part of a randomized controlled trial evaluating three knowledge translation strategies. Implementation Science, 4, 23

Dougherty, T. J.; Gomer, C. J.; Henderson, B. W.; Jori, G.; Kessel, D.; Korbelik, M.; Moan, J. \& Peng, Q. (1998). Photodynamic therapy, Journal of the National Cancer Institute, 90, $12,889-905$

Ebbesen, M. \& Jensen, T.G. (2006). Nanomedicine: Techniques, Potentials and Ethical Implications. Journal of Biomedicine and Biotechnology, Volume 2006, Article ID51516, Pages 1-11

Emerich, D.F. (2005). Nanomedicine: prospective therapeutic and diagnostic applications, Expert Opinion in Biological Therapy, 5(1):1-5

Emanuel, E.J. \& Menikoff, J. (2011). Reforming the Regulations Governing Research with Human Subjects. N Engl J Med, 2011 Jul 25.[Epub ahead of print. Last consulted on August 30th 2011. Available from:

http://www.ncbi.nlm.nih.gov/pubmed/21787202

European Environment Agency (EEA). (2001). Late lessons from early warnings: the precautionary principle 1896-2000. Environmental issue report $n^{\circ} 22$. Luxembourg: Office for Official Publications of the European Communities, 2001. ISBN 92-9167323-4. Last consulted on August 30th 2011. Available from: http://www.eea.europa.eu/publications/environmental_issue_report_2001_22

European Group on Ethics in Science and New Technologies to the European Commission (EGESNT/EC). (2007). Opinion on the ethical aspects of nanomedicine. Last consulted on August 30th 2011. Available from:

http:/ / ec.europa.eu/bepa/european-group-

ethics/docs/publications/opinion_21_nano_en.pdf

European Technology Platform on Nanomedicine (ETPM). (2006). Nanomedicine, Nanotechnology for Health. Strategic Research Agenda for Nanomedicine. Last consulted on August 30th 2011. Available from:

ftp://ftp.cordis.europa.eu/pub/nanotechnology/docs/nanomedicine_bat_en.pdf

Faure, A.C.; Hoffmann, C.; Bazzi, R.; Goubard, F.; Pauthe, E.; Marquette, C.; Blum, L.; Perriat, P.; Roux, S. \& Tillement, O. (2008). Functionalization of luminescent aminated particles for facile bioconjugation, ACS nano, 2(11):2273-82

Freitas, R.A. (2005). What is nanomedicine? Nanomedicine: Nanotechnology, Biology and Medicine, 1 (2005) 2-9. Last consulted on August 30th 2011. Available from: http://www.cs.duke.edu/bioComp/referencesFall07/Nanomedicine.pdf 
Genaidy, A.; Tolaymat, T.; Sequeira, R.; Rinder, M. \& Dionysiou, D. (2009). Health effects of exposure to carbon nanofibers: Systematic review, critical appraisal, meta analysis and research to practice perspectives. Science of the Total Environment, 407, 3686-3701

Glasgow, R.; Lichtenstein, E. \& Marcus, A. (2003). Why don't we see more translation of health promotion research to practice? Rethinking the efficacy-to-effectiveness transition. American Journal of Public Health, 93, 1261-1267

Gordon, N. \& Sagman, U. (2003). Nanomedicine Taxonomy. Canadian Institutes of Health Research \& Canadian NanoBusiness Alliance. Last consulted on August 30th 2011. Available from: http://www.pain.cz/nanomedicina/files/taxanomy.pdf

Graham, I.D.; Logan, J.; Harrison, M.B.; Straus, S.E.; Tetroe, J.; Caswell, W. \& Robinson, N. (2006). Lost in Knowledge Translation: time for a Map? The Journal of Continuing Education in the Health Professions, 26, 13-24

Gravier, J.; Schneider, R.; Frochot, C.; Bastogne, T.; Schmitt, F.; Didelon, J.; Guillemin, F. \& Barberi-Heyob, M. (2008). Improvement of m-THPC-like photosensitizer selectivity with Folate-based Targeted Delivery. Synthesis and in vivo Delivery Studies, Journal of Medical Chemistry, 51, 3867-3877

Hoppe, R. (2009). Risk and Uncertainty: Politics and Analysis. Proceedings of Governing Uncertainty: the contribution of social sciences to the governance of risks in environmental health, Conference held at Ecole des Mines, Paris, France, July 2009. Last consulted on August 30th 2011. Available from:

http://www.afsset.fr/upload/bibliotheque/935409038664891455468866124930/go verning_uncertainty_en.pdf

Haut Conseil de la Santé Publique (HCSP). (2009). Avis relatif à la sécurité des travailleurs lors de l'exposition aux nanotubes de carbone. 7 Janvier 2009. Last consulted on August 30th 2011. Available from :

http://www.hcsp.fr/docspdf/avisrapports/hcspa20090107_ExpNanoCarbone.pdf

Institute of Risk Management (IRM). (2002). A risk management standard. Published by AIRMIC, ALARM, IRM: 2002, London, UK. Last consulted on August 30th 2011. Available from:

http://www.theirm.org/publications/documents/Risk_Management_Standard_0 30820.pdf

Jardine, C.; Hrudev, S.; Shortreed, J.; Craig, L.; Krewski, D.; Furgal, C. \& McColl, S. (2003). Risk management framework for human health and environmental risks. J Toxicol Environ Health B Crit Rev. 2003 Nov-Dec;6(6):569-720

Kaluza, S.; Balderhaar, J.K.; Orthen B.; Honnert, B.; Rosell, M. G.; Tanarro, C.; Tejedor, J. \& Zugasti, A. (2008). Workplace exposure to nanoparticles. European Risks Observatory Literature Review. European Agency for Safety and Health at Work (EU-OSHA). Last consulted on August 30 th 2011. Available from: http://osha.europa.eu/en/publications/literature_reviews/workplace_exposure_ to_nanoparticles

Kateb, B.; Chiu, K.; Black, K.L.; Yamamoto, V.; Khalsa, B.; Ljubimova, J.Y.; Ding, H.; Patil, R.; Portilla-Arias, J.A.; Modo, M.; Moore, D.F.; Farahani, K.; Okun, M.S.; Prakash, N.; Neman, J.; Ahdoot, D.; Grundfest, W.; Nikzad, S. \& Heiss, J.D. (2011). Nanoplatforms for constructing new approaches to cancer treatment, imaging and drug delivery: what should be the policy? Neuroimage, 54 (1), 106-124

Kent, B.; Hutchinson, A.M. \& Fineout-Overholt, E. (2009). Getting evidence into practiceunderstanding knowledge translation to achieve practice change. Worldviews Evid Based Nurs. 6(3), 183-185 
Kon, A.A. (2008). The Clinical and Translational Science Award (CTSA) Consortium and the Translational Research Model. American Journal of Bioethics, 8(3), 58-60

Kopelman, L.M.; Resnick, D \& Weed D.L. (2004). What is the role of the precautionary principle in the philosophy od medicine and bioethics? J Med Philos., Jun:29(3):255-8

Lomas, J. (2007). The in-between world of knowledge brokering. BMJ, 334:1, 29-32

Manigat, R.; Wallet, F. \& André, J.C. (2010). From past to better public health programme planning for possible future global threats: case studies applied to infection control. Annalli dell' Istituto Superiori di Sanita, 46, 3, 228-235

Murphy, F.A.; Poland, C.A.; Duffin, R.; Al-Jamal, K.T.; Ali-Boucetta, H.; Nunes, A.; Byrne, F.; Prina-Mello, A.; Volkov, Y.; Li, S.; Mather, S.J.; Bianco, A.; Prato, M.; MacNee, W.; Wallace, W.A.; Kostarelos, K. \& Donaldson, K. (2011). Length-Dependent Retention of Carbon Nanotubes in the Pleural Space of Mice Initiates Sustained Inflammation and Progressive Fibrosis on the Parietal Pleura. The American Journal of Pathology, Volume 178, Issue 6, Pages 2587-2600

Oldham, G. \& McLean, R. (1997). Approaches to Knowledge Brokering. Last consulted on August 30th 2011. Available from: http://www.iisd.org/pdf/2001/networks_knowledge_brokering.pdf

Olson, K. (2008). The relationship between Stewardship Theory of Management and Employee Engagement: A case study exploration of the leadership philosophy of a professional services firm. Proceedings of the Midwest Academy of Management 2008 Annual Conference, St Louis, Missouri, October 2-4, 2008

Ortel, B.; Shea, C.R. \& Calzavara-Pinton, P. (2009). Molecular mechanisms of photodynamic therapy. Frontiers in bioscience : a journal and virtual library, 14, 4157-4172

Ostiguy, C.; Roberge, B.; Woods, C. \& Soucy, B. (2010). Engineered Nanoparticles: Current Knowledge about Occupational Health and Safety Risks and Prevention Measures. Studies and Research Projects. Report R-656. Institut de Recherche Robert-Sauvé en Santé et Sécurité du Travail (IRSST). Last consulted on August 30th 2011. Available from: http:/ / www.irsst.qc.ca/media/documents/PubIRSST/R-656.pdf

Plaetzer, K.; Krammer, B.; Berlanda, J.; Berr, F. \& Kiesslich, T. (2009). Photophysics and photochemistry of photodynamic therapy: fundamental aspects. Lasers Medical Science, 24(2), 259-268.

Poland, C.A.; Duffin, R.; Kinloch, I.; Maynard, A.; Wallace, W.A.H.; Seaton, A.; Stone, V.; Brown, S.; MacNee, W. \& Donaldson, K. (2008). Carbone nanotubes introduced into the abdominal cavity of mice show asbestos-like pathogenicity in a pilot study. Nature Nanotechnology, 3, 423-428

Sandhiya, S.; Dkhar, SA. \& Surendiran, A. (2009). Emerging trends in nano-medicine : an overview, Fundamental \& Clinical Pharmacology, 23(3), 263-269

Straus, S.; Tetro, J. \& Graham, I. (2009a). Power Point slideshow presentations from Knowledge translation in health care: moving from evidence to practice, Wiley-Blackwell, ISBN 978-1-4051-8106-8, UK. Last consulted on August 30th 2011. Available from: http://www.cihr-irsc.gc.ca/e/40618.html

Straus, S.; Tetro, J. \& Graham, I. (2009b). Knowledge translation is the use of knowledge in health care decision making. Journal of Clinical Epidemiology, 64, 6-10

Takagi, A.; Hirose, A.; Nishimura, T.; Fukumori, N.; Ogata, A.; Ohashi, N.; Kitajima, S. \& Kanno, J. (2008). Induction of mesothelioma in p53+/- mouse by intraperitoneal application of multi-wall carbon nanotube, The Journal of Toxicological Sciences, vol. $33: n^{\circ} 1,105-116$

Tirand, L.; Frochot, C.; Vanderesse, R.; Thomas, N.; Trinquet, E.; Pinel, S.; Viriot, M.L.; Guillemin, F. \& Barberi-Heyob, M. (2006). A peptide competing with VEGF165 
binding on neuropilin-1 mediates targeting of a chlorin-type photosensitizer and potentiates its photodynamic activity in human endothelial cells, Journal of Controlled Release, 111, 153-164

Thomas, N.; Bechet, D.; Becuwe, P.; Tirand, L.; Vanderesse, R.; Frochot, C.; Guillemin, F. \& Barberi-Heyob, M. (2009). Peptide conjugated chlorin-type photosensitizer binds neuropilin-1 in vitro and in vivo, Journal of Photochemistry and Photobiology B: Biology, 96, 101-108

Triesscheijn, M.; Baas, P.; Schellens, J.H.M. \& Stewart, F.A. (2006). Photodynamic therapy in oncology, The Oncologist, 11, 1034-1044

UT Southwestern University Medical Centre Web site (UTSUMC). (2011). What is Translational Research? Continuum of Biomedical Research, Original Figure adapted from the National Center for Research Resources Strategic Plan 2009-2013, Last consulted on August 30th 2011. Available from: http:/ / www.utsouthwestern.edu/utsw/cda/dept440996/files/489751.html

Van Asselt, M.B.A. (2000), as cited in Hoppe, R. (2009). Risk and Uncertainty: Politics and Analysis. Proceedings of Governing Uncertainty: the contribution of social sciences to the governance of risks in environmental health, Conference held at Ecole des Mines, Paris, France, July 2009

Van Asselt, M.B.A.; Huijs, S. \& Van't Klooster, S.A. (2002). The intriguing relationship between uncertainties and normativity: the need for pluralistic assessments. Paper prepared for a workshop Normativitat und Unsicherheit, University of Stuttgardt, Germany, February 2002. Last consulted on August 30th 2011. Available from: http:/ / www.uni-stuttgart.de/philo/ngm/van.pdf

Vanderesse, R.; Frochot, C.; Barberi-Heyob, M.; Richeter, S.; Raehm, L. \& Durad, J.O. (2011). Eds. Nanoparticles for Photodynamic Therapy Applications. A. Prokop (ed.), Intracellular Delivery: Fundamentals and Applications, Fundamental Biomedical Technologies 5, DOI 10.1007/978-94-007-1248-5_19, (C) Springer Science+Business Media B.V.

Verhille, M.; Couleaud, P.; Vanderesse, R.; Brault, D.; Barberi-Heyob, M. \& Frochot, C. (2010). Modulation of photosensitization processes for an improved targeted photodynamic therapy. Current Medicinal Chemistry, 2010, 17, (32), 3925-3943

Wang, M. \& Thanou, M. (2010). Targeting nanoparticles to cancer, Pharmacological Research, $62,90-99$

Weed, D.L. (2004). Methodologic implications of the Precautionary Principle: causal criteria. Int J Occup Med Environ Health (2004);17(1):77-81

Westerholm, P. (2010). The ethical challenges of the occupational physician in our time, G. Ital. Med. Lav. Erg. 32:4, 403-406

Wilkinson, A.; Papaioannou, D.; Keent, C. \& Booth, A. (2009). The role of the information specialist in supporting knowledge transfer: a public health information case study. Health Information and Libraries Journal, 26, 118-125

Wolf, S.M. \& Jones, C.M. (2011). Designing Oversight for Nanomedicine Research in Human Subjects: Systematic Analysis of Exceptional Oversight for Emerging Technologies, Journal of Nanoparticle Research, Forthcoming; Minnesota Legal Studies Research Paper $\mathrm{N}^{\circ}$. 11-04. Last consulted on August 30th 2011. Available from: http:// papers.ssrn.com/sol3/papers.cfm?abstract_id=1744336

Woolf, S.H. (2008). The Meaning of Translational Research and Why It Matters. JAMA, 299(2), 211-213 


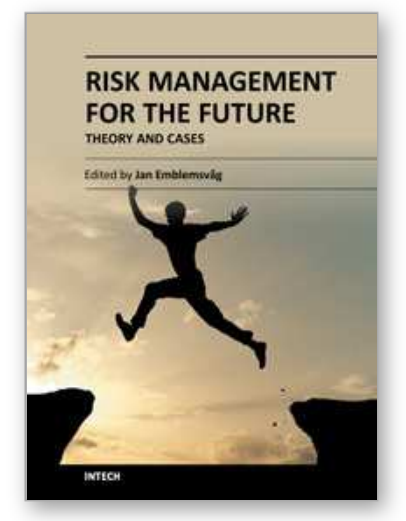

\author{
Risk Management for the Future - Theory and Cases \\ Edited by Dr Jan Emblemsvåg
}

ISBN 978-953-51-0571-8

Hard cover, 496 pages

Publisher InTech

Published online 25, April, 2012

Published in print edition April, 2012

A large part of academic literature, business literature as well as practices in real life are resting on the assumption that uncertainty and risk does not exist. We all know that this is not true, yet, a whole variety of methods, tools and practices are not attuned to the fact that the future is uncertain and that risks are all around us. However, despite risk management entering the agenda some decades ago, it has introduced risks on its own as illustrated by the financial crisis. Here is a book that goes beyond risk management as it is today and tries to discuss what needs to be improved further. The book also offers some cases.

\title{
How to reference
}

In order to correctly reference this scholarly work, feel free to copy and paste the following:

Roberte Manigat, Florent Allix, Céline Frochot and Jean Claude André (2012). Preventing Societal Health Risks Emerging in the Development Of Nanomedicine - What Should Prevail?, Risk Management for the Future - Theory and Cases, Dr Jan Emblemsvåg (Ed.), ISBN: 978-953-51-0571-8, InTech, Available from: http://www.intechopen.com/books/risk-management-for-the-future-theory-and-cases/preventing-occupationalenvironmental-and-more-broadly-societal-health-risks-emerging-in-the-develo

\section{INTECH}

open science | open minds

\section{InTech Europe}

University Campus STeP Ri

Slavka Krautzeka 83/A

51000 Rijeka, Croatia

Phone: +385 (51) 770447

Fax: +385 (51) 686166

www.intechopen.com

\section{InTech China}

Unit 405, Office Block, Hotel Equatorial Shanghai

No.65, Yan An Road (West), Shanghai, 200040, China

中国上海市延安西路65号上海国际贵都大饭店办公楼405单元

Phone: +86-21-62489820

Fax: +86-21-62489821 
(C) 2012 The Author(s). Licensee IntechOpen. This is an open access article distributed under the terms of the Creative Commons Attribution 3.0 License, which permits unrestricted use, distribution, and reproduction in any medium, provided the original work is properly cited. 